\title{
The Contingency of Cocaine Administration Accounts for Structural and Functional Medial Prefrontal Deficits and Increased Adrenocortical Activation
}

\author{
미ason J. Radley, ${ }^{1,2}$ - Rachel M. Anderson, ${ }^{1}$ Caitlin V. Cosme, ${ }^{1}$ Ryan M. Glanz, ${ }^{1}$ Mary C. Miller, ${ }^{1}$ Sara A. Romig-Martin, \\ and Ryan T. LaLumiere ${ }^{1,2}$ \\ ${ }^{1}$ Department of Psychological and Brain Sciences and 2 Interdisciplinary Neuroscience Program, University of Iowa, Iowa City, Iowa 52242
}

\begin{abstract}
The prelimbic region $(\mathrm{PL})$ of the medial prefrontal cortex $(\mathrm{mPFC})$ is implicated in the relapse of drug-seeking behavior. Optimal mPFC functioning relies on synaptic connections involving dendritic spines in pyramidal neurons, whereas prefrontal dysfunction resulting from elevated glucocorticoids, stress, aging, and mental illness are each linked to decreased apical dendritic branching and spine density in pyramidal neurons in these cortical fields. The fact that cocaine use induces activation of the stress-responsive hypothalamo-pituitaryadrenal axis raises the possibility that cocaine-related impairments in mPFC functioning may be manifested by similar changes in neuronal architecture in mPFC. Nevertheless, previous studies have generally identified increases, rather than decreases, in structural plasticity in $\mathrm{mPFC}$ after cocaine self-administration. Here, we use 3D imaging and analysis of dendritic spine morphometry to show that chronic cocaine self-administration leads to mild decreases of apical dendritic branching, prominent dendritic spine attrition in PL pyramidal neurons, and working memory deficits. Importantly, these impairments were largely accounted for in groups of rats that self-administered cocaine compared with yoked-cocaine- and saline-matched counterparts. Follow-up experiments failed to demonstrate any effects of either experimenter-administered cocaine or food self-administration on structural alterations in PL neurons. Finally, we verified that the cocaine self-administration group was distinguished by more protracted increases in adrenocortical activity compared with yoked-cocaine- and saline-matched controls. These studies suggest a mechanism whereby increased adrenocortical activity resulting from chronic cocaine self-administration may contribute to regressive prefrontal structural and functional plasticity.
\end{abstract}

Key words: corticosterone; dendritic spine; HPA; prelimbic; self-administration; working memory

Significance Statement

Stress, aging, and mental illness are each linked to decreased prefrontal plasticity. Here, we show that chronic cocaine selfadministration in rats leads to decrements in medial prefrontal structural and functional plasticity. Notably, these impairments were largely accounted for in rats that self-administered cocaine compared with yoked counterparts. Moreover, we verified previous reports showing that adrenocortical output is augmented by cocaine administration and is more protracted in rats that were permitted to receive the drug contingently instead of passively. These studies suggest that increased adrenocortical activity resulting from cocaine self-administration may contribute to regressive prefrontal structural and functional plasticity.

\section{Introduction}

A considerable amount of research has focused on understanding the role of the prefrontal cortex in the neurobiology of cocaine

\footnotetext{
Received Dec. 3, 2014; revised July 17, 2015; accepted July 20, 2015.

Author contributions: J.J.R., R.M.A., C.V.C., and R.T.L. designed research; J.J.R., R.M.A., C.V.C., and S.A.R.-M. performed research; J.J.R., R.M.A., C.V.C., R.M.G., M.C.M., S.A.R.-M., and R.T.L. analyzed data; J.J.R. and R.T.L. wrote the paper.

This work was supported by the National Institutes of Health (Grants USPHS DA034684 to R.T.L. and MH095972 to J.J.R.).

The authors declare no competing financial interests.

Correspondence should be addressed to Jason Radley, Department of Psychology, University of lowa, E11 Seashore Hall, lowa City, IA 52242. E-mail: Jason-radley@uiowa.edu.
}

addiction. Imaging studies in cocaine addicts reveal decreases in prefrontal gray matter density and diminished metabolic activity during non-drug-related tasks in prefrontal cortical and associated frontal networks (Goldstein and Volkow, 2011), whereas animal studies have identified the prelimbic area (PL) of the medial prefrontal cortex (mPFC) as a critical brain region driving the relapse to drug-seeking behavior (McFarland and Kalivas, 2001; LaLumiere and Kalivas, 2008; Stefanik et al., 2013). Collectively, these studies suggest that cocaine administration may ini- 
tiate the reorganization of prefrontal networks, thereby contributing to the process of compulsive drug use (Jentsch and Taylor, 1999).

Optimal functioning of mPFC relies on excitatory synaptic connections involving dendritic spines in pyramidal neurons (Goldman-Rakic, 1995; Morrison and Baxter, 2012). It has been widely documented that pyramidal neurons in MPFC undergo dendritic shortening, spine loss, and prefrontal functional impairment after prolonged stress and/or exposure to adrenocortical hormones (Wellman, 2001; Liston et al., 2006; Liu and Aghajanian, 2008; Hains et al., 2009; Gourley et al., 2013). That acute and repeated cocaine administration induce activation of the stress-responsive hypothalamo-pituitary-adrenal (HPA) axis and sensitized HPA responses, respectively (Rivier and Vale, 1987; Mendelson et al., 1992; Mantsch et al., 2007), suggest that elevated adrenocortical activity during repeated cocaine administration may contribute to prefrontal network reorganization. Support for this idea may also derive from determining whether drug regimens that differentially activate the HPA axis are accompanied by distinct structural outcomes in MPFC because several studies highlight augmented HPA output in rats selfadministering cocaine compared with yoked counterparts receiving the same amount of drug (Broadbear et al., 1999; Galici et al., 2000).

To date, a number of studies have examined the relationship between repeated cocaine administration and gross morphology of mPFC neurons (for review, see Robinson and Kolb, 2004). However, much of this knowledge is based on quantification of dendritic spines using manual counting methods performed in Golgi-labeled material that undersample spine densities in cortical neurons and systematically undersample thin subtypes (for discussion, see Dumitriu et al., 2012). Because thin spines comprise the majority of the total spine population in cortical pyramidal neurons (Harris and Stevens, 1989; McEwen and Morrison, 2013) and are implicated in optimal prefrontal network functioning (Arnsten et al., 2010; Dumitriu et al., 2010), lowerresolution methods for visualizing dendritic spines are limited in their capacity to identify the key structural synaptic attributes resulting from repeated cocaine administration.

Here, we critically examined the effects of chronic cocaine self-administration on structural plasticity in PL using a highthroughput 3D morphometric analysis of dendritic spines (Rodriguez et al., 2006; Radley et al., 2008). Whereas 2 weeks of cocaine self-administration resulted in diminished structural plasticity in PL neurons and accompanying working memory impairments, these effects were largely absent in the yokedcocaine group compared with saline-treated controls. Moreover, we verified previous reports showing that adrenocortical output is augmented by cocaine administration and is more protracted in rats that were permitted to receive the drug contingently instead of passively. Collectively, these data suggest that increased adrenocortical activity resulting from cocaine self-administration may contribute to regressive prefrontal structural and functional plasticity.

\section{Materials and Methods}

Animals

Male Sprague Dawley rats (9-10 weeks and 250-275 g at time of arrival; Charles River Laboratories) were single-housed in an AAALACapproved vivarium on a $12 \mathrm{~h}$ reverse light/dark cycle (lights off at 1800) with ad libitum access to food and water. All rats were acclimated to their housing facility for a minimum of $5 \mathrm{~d}$ before undergoing surgery. All procedures were in accordance with the National Institutes of Health's
Guide for the Care and Use of Laboratory Animals and approved by the University of Iowa Institutional Animal Care and Use Committee.

\section{Cocaine self-administration}

The procedures performed are based upon previous reports (McFarland et al., 2003; LaLumiere and Kalivas, 2008; LaLumiere et al., 2012). To allow for the repeated administration of cocaine, rats were implanted with indwelling jugular catheters $7 \mathrm{~d}$ before drug reinforcement training. Rats were anesthetized with ketamine $(100 \mathrm{mg} / \mathrm{kg}$, i.m.) and xylazine (6 $\mathrm{mg} / \mathrm{kg}$, i.m.). Ketorolac ( $3 \mathrm{mg} / \mathrm{kg}$ ) was given as an analgesic on the day of surgery and the day immediately after surgery. For implantation of intravenous catheters, a $13 \mathrm{~cm}$ piece of beveled SILASTIC tubing was slid subcutaneously from the dorsal to the ventral side of the rat and the beveled end of the tubing was inserted into the left jugular vein. A silicone ball was adhered to the SILASTIC tubing $4 \mathrm{~cm}$ from the beveled end of the catheter to serve as a stopping point during insertion. Catheters were secured in place using silk sutures. The nonbeveled end of the catheter was externalized through a small hole in the skin between the rat's shoulder blades and was connected to a 22 gauge guide cannula that was affixed in the middle of a harness which was looped around the rat's forelimbs. Immediately after surgery, rats were administered $3 \mathrm{ml}$ of sterile saline subcutaneously and received a local anesthetic (bupivacaine). Rats were then returned to their home cages and permitted to recover for 5-7 d before the initiation of any behavioral procedures. During the interim, catheters were flushed daily with $0.1 \mathrm{ml}$ of heparinized saline (100 USP) to ensure catheter patency and $0.1 \mathrm{ml}$ of cefazolin $(100 \mathrm{mg} / \mathrm{ml})$ to reduce the risk for postsurgery infection.

All self-administration experiments occurred in standard operant chambers (Med Associates) that were equipped with two retractable levers, two cue lights, a house light, and a tone generator $(4500 \mathrm{~Hz})$. Before the start of self-administration training, rats were randomly assigned to either the cocaine self-administration group or a yoked group (cocaine or saline). All rats, regardless of group assignment, were food deprived for $24 \mathrm{~h}$ before a $15 \mathrm{~h}$ overnight food-training session, during which each active lever press resulted in a single food pellet $(45 \mathrm{mg})$ on a fixed-ratio 1 (FR1) schedule. After the completion of food training, rats were maintained on $\sim 20 \mathrm{~g}$ of food daily, which was continued for the duration of self-administration training. Before the start of self-administration training, intravenous catheters from each rat were checked for patency using $0.1 \mathrm{ml}$ of sodium brevital $(1 \mathrm{mg} / \mathrm{ml})$, which produces a momentary loss of the righting reflex.

Training sessions all lasted $2 \mathrm{~h}$, during which an active and inactive lever was present, along with the illumination of a house light. For rats in the self-administration group, one press of the active lever resulted in a single infusion of cocaine $(50 \mu \mathrm{l}$ infusion of $200 \mu \mathrm{g}$ of cocaine $\mathrm{HCl}$ dissolved in sterile saline given over $2.18 \mathrm{~s}$; cocaine kindly provided by the National Institute on Drug Abuse, NIDA) and a 5 s light and tone cue on an FR1 schedule. A $20 \mathrm{~s}$ timeout period followed each infusion. Inactive lever presses had no consequence. Rats in the yoked groups received noncontingent infusions of either cocaine or saline through a direct yoking procedure to the self-administering rats or through a preprogrammed session patterned after previous self-administration infusions in rats given contingent cocaine. For rats in the yoked groups, presses on the active and inactive lever had no consequences. Rats underwent daily self-administration $6 \mathrm{~d}$ a week for a minimum of $12 \mathrm{~d}$. To conclude training, each group of rats was required to receive at least 10 infusions of cocaine or saline per day for at least $10 \mathrm{~d}$, including the last $3 \mathrm{~d}$ of self-administration, and to demonstrate discrimination between the active and inactive lever.

Experiment 1: Fluorescent dye-filling and morphometric analyses after repeated cocaine self-administration

Histology and tissue processing. At the end of the daily cocaine selfadministration procedure, all three groups of rats (yoked-saline, yokedcocaine, cocaine self-administration) were returned to their home cages and restored to ad libitum access to food. Two weeks later, rats were anesthetized with sodium pentobarbital $(100 \mathrm{mg} / \mathrm{kg}$, i.p.) and perfused with $100 \mathrm{ml}$ of $1 \%$ paraformaldehyde and $0.125 \%$ glutaraldehyde in $0.1 \mathrm{M}$ PBS, pH 7.4, followed by $500 \mathrm{ml}$ of $4 \%$ paraformaldehyde and $0.125 \%$ 
glutaraldehyde in $0.1 \mathrm{M}$ PBS, pH 7.4, at a flow rate of $55 \mathrm{ml} / \mathrm{min}$. The descending aorta was clamped to limit the flow of fixative to the head and upper extremities and to prevent fixation of the adrenal glands. Immediately after perfusions, the adrenal glands were extracted and weighed and brains were removed and postfixed for 3-4h. After postfixation, the pregenual pole of the cortex was sectioned coronally into $250-\mu \mathrm{m}$-thick slabs using an oscillating tissue slicer (VT-1000S; Leica) and was stored in $0.1 \mathrm{M}$ PBS containing $0.1 \%$ sodium azide at $4^{\circ} \mathrm{C}$ until the time of cell loading.

Intracellular dye injections. The procedures used here are based on previous reports using the same methodology (Radley et al., 2006; Radley et al., 2008; Anderson et al., 2014). Coronal tissue slabs were treated in the DNA-binding fluorescent stain 4',6-diamidino-2-phenylindole (DAPI, Invitrogen) to distinguish between nuclear lamination patterns that distinguish PL from other adjacent-lying prefrontal cortical subfields. DAPI-treated sections were mounted on nitrocellulose filter paper, submerged in a tissue culture dish containing $0.1 \mathrm{M}$ PBS, and viewed under fluorescence using a fixed-stage microscope (Leica DM5500). Injections of $5 \%$ Lucifer yellow (Life Technologies) were made by iontophoresis through micropipettes (1-2 $\mu \mathrm{m}$ inner diameter) under a DC current of 1-6 nA for 5-10 min. The general technique for cell filling involved carefully observing the passive diffusion of LY resulting from application of a negligibly small amount of current from the advancing micropipette tip under $40 \times$ magnification. LY diffuses amorphously until hitting a dendritic process or cell body, whereby the dye becomes restricted intracellularly. After several neurons were filled intracellularly, tissue sections were mounted onto glass slides and coverslipped in Vectashield (Vector Laboratories).

Neurons in layers $2 / 3$ and 5 were selected for the PL dye injection procedure based upon the distinguishing cytoarchitectonic features of this region, notably a more densely packed layer 2 and a broader layer 5 . Neurons in lateral orbitofrontal cortex (LO) and motor cortex (M1-2) were also selected for dye filling to provide additional information about treatment effects on dendritic spine alterations in other frontal cortical structures. LO was identified as occupying the region immediately caudal to the union of the olfactory bulb and hemispheric frontal pole beginning in the dorsal bank of the fundus of the rhinal sulcus and extending laterally. M1 was readily identified as occupying a large swath of the dorsal surface of the frontal hemisphere.

Digital reconstructions of PL neurons. Pyramidal neuron dendritic arbors from layers $2 / 3$ of PL were reconstructed in 3D using a computerassisted morphometry system consisting of a Leica DM4000R equipped with an Applied Scientific Instrumentation MS-2000 XYZ computercontrolled motorized stage, a QImaging Blue digital camera, a Gateway computer, and morphometry software. Neurons were visualized and the dendritic tree was reconstructed using a Leica Apochromat $40 \times$ objective with a numerical aperture (NA) of 1.4 and Neurolucida software (MBF Biosciences). All reconstructions and analyses were performed by an experimenter unaware of the treatment condition for each rat.

A series of strict criteria were used for inclusion of pyramidal neuron apical and basal dendrites for morphologic analysis. To be considered for analysis, LY-filled PL neurons had to exhibit complete filling of the dendritic tree, as evidenced by well defined endings. For apical dendrites, the fact that the primary shaft generally coursed parallel or gently downward from the top surface of the section (i.e., sections were flipped in instances where apical dendrites coursed upward out of the top surface of the section) optimized the probability for retaining complete dendritic arbors. However, because the dye-filling procedure was performed in sections that were only $250 \mu \mathrm{m}$ thick, it was virtually impossible to retain an entirely intact apical dendritic arbor with no truncations. Therefore, apical dendrites included in the analysis retained intact secondary and tertiary branches, with truncations permitted only in collateral branches that appeared to be nearing the point of termination or were deemed unlikely to make any significant bifurcations. These criteria prohibited the inclusion of layer 5 PL neurons in dendritic morphologic analyses because the apical dendritic trees in this subpopulation traverse significantly greater distances than layer $2 / 3$ neurons $(450-500 \mu \mathrm{m}$ vs $250-350$ $\mu \mathrm{m})$ before reaching the pial surface.

PL neurons in layers 2 and 3 exhibited some qualitative differences in their gross dendritic morphology; deeper-lying layer 3 neurons possessed apical dendrites with elongated primary dendrites before the first truncation point $(\sim 75-125 \mu \mathrm{m}$, notwithstanding collateral branching), whereas more superficially situated layer 2 neurons contained shorter distances to the first branch point $(\sim 25-75 \mu \mathrm{m})$. Nevertheless, consideration of these subsets as morphologically distinct subpopulations in ancillary analyses failed to demonstrate any quantitative differences that warranted partitioning them into distinct groupings. For basal dendrites, it was common to retain an average of 1-3 entirely intact arbors for a given LY-filled neuron so analyses on intact branches were performed for this category.

Confocal laser scanning microscopy and dendritic spine analysis. 2D renderings for neurons in PL, LO, and M1 were obtained using Neurolucida software and a radial distance of $150 \mu \mathrm{m}$ from the soma was selected as the boundary delineating proximal and distal portions of the dendritic tree. Within these regions, branches were randomly selected for each neuron for an average of three segments per neuron and five neurons for each rat. The selection criteria for confocal imaging of dendritic segments are based upon previous reports (Radley et al., 2006; Radley et al., 2008) and were as follows: (1) possess a diameter of $<3 \mu \mathrm{m}$ because largerdiameter dendrites in pyramidal neurons exhibit greater variability in spine density values, (2) reside within a depth of $70 \mu \mathrm{m}$ from the top surface of the section due to the limited working distance of the optical system, (3) be either parallel to or course gently relative to the coronal surface of the section (i.e., this helps to minimize $z$-axis distortion and facilitate the unambiguous identification of spines), and (4) have no overlap with other branches that would obscure visualization of spines. $z$-stacks were collected on a Leica SP5 confocal laser-scanning microscope equipped with an argon laser and a $100 \times, 1.4 \mathrm{NA}$ oil-immersion objective using voxel dimensions of $0.1 \times 0.1 \times 0.1 \mu \mathrm{m}^{3}$. Settings for pinhole size ( 1 airy disc), gain, and offset were optimized initially and then held relatively constant throughout the study to ensure that all images were digitized under similar illumination conditions at a resolution of $512 \times 512$ pixels.

Images were deconvolved with AutoDeblur (Media Cybernetics) and spine analyses were performed using the semiautomated software NeuronStudio (Rodriguez et al., 2006; Radley et al., 2008; http://research. mssm.edu/cnic/tools-ns.html), which analyzes in 3D dendritic length, spine density, and morphometric features (i.e., head/neck diameter, length, subtype) for each dendritic spine. Spines were classified as thin or mushroom if the ratio of the head diameter-to-neck diameter was $>1.1$. If their ratio exceeded this value, spines with a maximum head diameter $>0.4 \mu \mathrm{m}$ were classified as mushroom or were classified as thin. Spines with head-to-neck diameter ratios $<1.1$ were also classified as thin if the ratio of spine length-to-neck diameter was $>2.5$, otherwise they were classified as stubby. A fourth category, filopodial spines, were considered to have a long and thin shape with no enlargement at the distal tip, were very seldom observed, and were classified as thin. Finally, data readouts from the spine analysis algorithm were visually compared by the experimenter for each optical stack to verify accurate subtype classifications for dendritic spines.

\section{Experiment 2: Dendritic and spine morphometric analyses after} repeated cocaine injections

In a separate experiment, we used a commonly used cocaine administration protocol to test the capacity of noncontingent cocaine administration to induce structural alterations in mPFC neurons (Robinson and Kolb, 1999; Lee et al., 2006; LaPlant et al., 2010). Rats were housed in pairs in a 12:12 light-dark cycle (lights on at 06:00) and given ad libitum access to food. After $5 \mathrm{~d}$ of daily handling, groups of rats were given repeated intraperitoneal injections of $15 \mathrm{mg} / \mathrm{kg}$ cocaine $\mathrm{HCl}(n=8$; cocaine provided by NIDA) or saline vehicle injections of the same volume $(n=8)$. Injections were $5 \mathrm{~d}$ /week for a 4 -week period and then remained for another 4 weeks before tissue harvesting for the cell-loading procedures, as described above.

\section{Experiment 3: Dendritic and spine morphometric analyses after food self-administration}

This series of experiments was conducted to address the possibility that another type of reinforcement learning could explain the structural def- 
icits that were observed in PL neurons after repeated cocaine selfadministration. As in the foregoing cocaine self-administration experiments, rats were acclimated for 5-7 $\mathrm{d}$ before the initiation of operant behavioral training. All food self-administration experiments were conducted in the same operant chambers described above. Before the start of self-administration training, rats were randomly assigned to either the food self-administration $(n=7)$ group or the yoked-food $(n=5)$ group. All rats, regardless of group assignment, were food deprived $24 \mathrm{~h}$ prior to their first training session. Rats in the food experiment did not undergo overnight food training before the start of self-administration procedures. Throughout the course food self-administration, all rats were maintained on $\sim 20$ g of food daily.

Training sessions were identical to those performed for cocaine selfadministration, with the exception that pressing the active lever produced a single food pellet along with the $5 \mathrm{~s}$ light and tone cue (FR1 schedule). A 20 s timeout period followed the delivery of each food pellet and pressing of the inactive lever had no consequence. Yoked-food rats were paired with a self-administering rat and received a single food pellet each time their partner self-administered a food pellet. Rats underwent daily self-administration sessions $6 \mathrm{~d}$ a week for a minimum of $12 \mathrm{~d}$. To conclude training, both groups of rats were required to receive at least 50 food pellets per day for at least $10 \mathrm{~d}$, including the last $3 \mathrm{~d}$ of selfadministration, and to demonstrate discrimination between the active and inactive lever. After the completion of the self-administration training, rats were given food and water ad libitum until perfusion and tissue harvesting for the cell-loading procedure.

\section{Experiment 4: Examination of adrenocortical and prefrontal functional alterations after cocaine self-administration}

Blood collection and radioimmunoassay. To assay for changes in adrenocortical activity as a function of repeated cocaine administration, plasma corticosterone was repeatedly sampled from yoked-saline, yoked-cocaine, and cocaine self-administration rats on the first and last days of cocaine self-administration (days 1 and 12). Blood samples were taken immediately before each self-administration session and at 0,30 , and $60 \mathrm{~min}$ after the end of the entire $2 \mathrm{~h}$ self-administration session. For blood collection, rats were restrained briefly $(\sim 15-30 \mathrm{~s})$ and a small longitudinal incision was made at the distal tip of the tail with a sterile blade. Whereas previous reports have shown that contingent cocaine administration produces enhanced HPA axis activation compared with noncontingent drug exposure (Broadbear et al., 1999; Galici et al., 2000), we did not perform repeated blood sampling during the actual drug administration sessions because our method of blood collection would have disrupted the behavior. Blood samples $(\sim 200 \mu \mathrm{l})$ were collected into chilled plastic Microfuge tubes containing EDTA and aprotinin, centrifuged, and fractionated for storage of plasma at $-80^{\circ} \mathrm{C}$ until assayed. Plasma corticosterone was measured without extraction using an antiserum raised in rabbits against a corticosterone-BSA conjugate, and ${ }^{125} \mathrm{I}$-corticosterone-BSA as tracer (MP Biomedicals). Assay sensitivity was $0.8 \mu \mathrm{g} / \mathrm{dl}$; intra-assay and inter-assay coefficients of variation were $5 \%$ and $10 \%$, respectively.

Delayed alternation testing. After the last day of the self-administration procedure, rats were returned to their home cages for 2 weeks and allowed ad libitum access to food throughout this time. Thereafter, they were again placed on a restricted diet $(\sim 20 \mathrm{~g} / \mathrm{d})$ and trained in a prefrontal-dependent spatial working memory task: delayed alternation using a T-maze (Ramos et al., 2003; Anderson et al., 2014).

Rats were first habituated to a T-maze $(90 \times 65 \mathrm{~cm} ; 40 \mathrm{~cm}$ opaque walls surrounding the perimeter) over a several-day period using miniature chocolate chips as a food reward for running to either goal arm in $<60$ s. Next, rats were subjected to a forced alternation period of training where they were only rewarded with chocolate after entering the opposite goal arm that they were in previously. Between trials, the maze was wiped clean with $95 \%$ ethanol to prevent olfactory cues from determining choice. After 3 consecutive days of 10 trials/d, rats were trained until they could spontaneously alternate between goal arms (i.e., chocolate was present in both goal arms, although rats were only rewarded for entering the opposite arm from the previous trial). Once training criterion was reached, testing involved 8 trials/d over 6 consecutive days. The delays
Table 1. Body weight, adrenal weight, and drug infusion data for prefrontal structural analyses

\begin{tabular}{lccc}
\hline Measure & $\begin{array}{l}\text { Yoked } \\
\text { saline }\end{array}$ & $\begin{array}{l}\text { Yoked } \\
\text { cocaine }\end{array}$ & $\begin{array}{l}\text { SA } \\
\text { cocaine }\end{array}$ \\
\hline No. rats per group & 15 & 15 & 22 \\
Starting weight $(\mathrm{g})$ & $310 \pm 6$ & $304 \pm 6$ & $313 \pm 4$ \\
Total weight gain $(\mathrm{g})$ & $153 \pm 7$ & $130 \pm 10$ & $124 \pm 10^{*}$ \\
$\quad$ SA period (first $14 \mathrm{~d})$ & $35 \pm 4$ & $29 \pm 5$ & $33 \pm 4$ \\
$\quad$ Withdrawal period $(15-28 \mathrm{~d})$ & $118 \pm 8$ & $101 \pm 11$ & $91 \pm 11$ \\
Adrenal weight $(\mathrm{mg})$ & $57 \pm 2$ & $58 \pm 2$ & $64 \pm 2 \dagger$ \\
Adrenal: body weight $(\mathrm{mg} / \mathrm{g} \times 100)$ & $12.4 \pm 0.5$ & $13.6 \pm 0.7$ & $14.8 \pm 0.5^{*}$ \\
No. of infusions $(12 \mathrm{~d}$ average) & $26 \pm 1$ & $25 \pm 1$ & $25 \pm 1$ \\
Avg. daily cocaine treatment $(\mathrm{mg} / \mathrm{kg})$ & $\mathrm{N} / \mathrm{A}$ & $15.4 \pm 0.7$ & $15.4 \pm 0.8$ \\
\hline
\end{tabular}

Data represent mean $\pm S E M ;{ }^{*} p<0.05$ with respect to yoked-saline group; $t p<0.05$ with respect to yoked-saline and yoked-cocaine treatments.

SA, Self-administrated.

between each trial were semirandomly varied at 15,30 , or $60 \mathrm{~s}$ (on a given day, the same pattern was used for all rats). During the delay interval, rats were placed in the holding cage and the maze was cleaned with $95 \%$ ethanol. The percentage of correct choice alternations made at each delay interval $(15,30,60 \mathrm{~s})$ was obtained for each rat and overall averages were expressed as a function of treatment group.

\section{Statistics}

Data from the dendritic branch (i.e., layer 2/3 PL neurons) and spine morphometric (i.e., layers $2 / 3$ and $5 \mathrm{PL}, \mathrm{LO}$, and M1) experiments were averaged from each rat (3-4 segments/neuron, 5 neurons/rat, 5-9 rats per group; see figure legends for numbers of animals used for each analysis) as a function of treatment status. The final group sizes for the structural plasticity experiment were lower than our starting values shown in Table 1 . This difference is due to the fact that different subpopulations of neurons were used for dendritic and spine morphologic analyses (e.g., only layer 2/3 PL neurons were analyzed for dendritic morphology) and that the success rate from perfused rats that yield suitable numbers of fluorescent dye-filled neurons for inclusion into the analysis is $\sim 65$ $75 \%$. Finally, attempts made to fill cells in LO and M1 were only performed in a subset of this total cohort.

The effects on overall dendritic length, number of branch endings, and dendritic spine and subtype densities were compared with a one-way ANOVA as a function of treatment group. Blood corticosterone levels at each time interval (at pretraining and 0, 30, and 60 min posttraining; days 1 and 14) and delayed alternation performance at each interval $(15,30$, and $60 \mathrm{~s}$ ) were compared using a repeated-measures ANOVA with factors of treatment group (cocaine self-administration, yoked-cocaine, yoked-saline) and the time intervals as within-subjects factors for the corticosterone data (minimum days for corticosterone data; 15, 30, and $60 \mathrm{~s}$ for delayed alternation data). All pairwise comparisons were made using Fisher's least-significant difference with significance set at $p<0.05$ and data are expressed as mean + SEM. Cumulative distribution differences for certain spine parameters (length, head diameter, volume, mushroom head diameter, mushroom volume, thin head diameter, thin length) were evaluated using the Kolmogorov-Smirnov test with MATLAB software.

\section{Results}

\section{Cocaine self-administration induces regressive structural} plasticity in PL neurons

Characterization of rats chronically given cocaine

Rats underwent cocaine self-administration for $14 \mathrm{~d}$, with $62 \mathrm{~h}$ daily sessions per week or served as yoked-saline or yokedcocaine control rats. The yoked groups received passive infusions of either saline or cocaine in a similar temporal pattern as their counterparts receiving contingent cocaine (i.e., via direct yoking or preprogrammed infusions based upon previous selfadministration behavior). The mean number of daily cocaine infusions was comparable across groups $(25 \pm 1$; Fig. 1) and the 

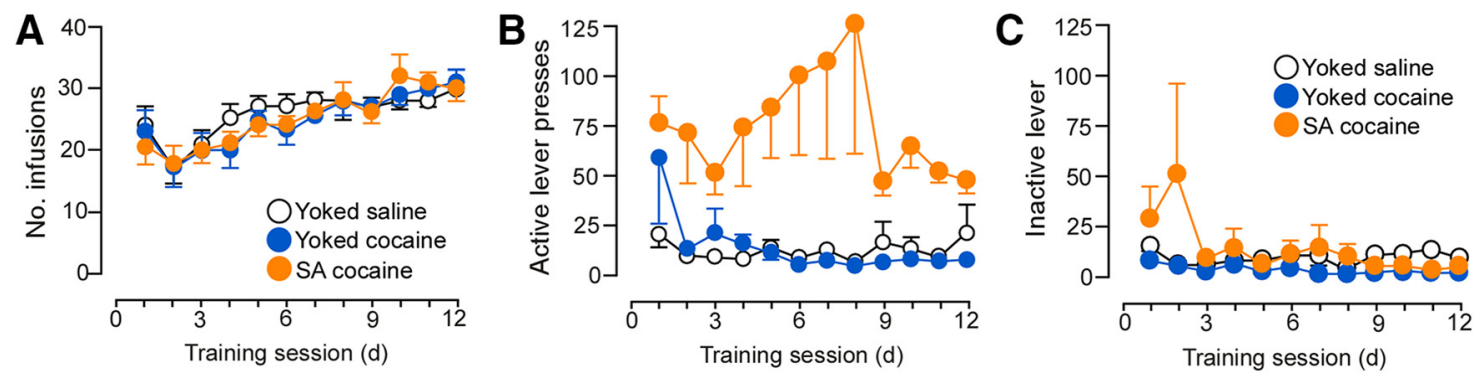

Figure 1. Line graphs displaying operant and infusion data from rats included in the dendritic spine morphologic analyses. Rats underwent cocaine self-administration (SA cocaine) in daily $2 \mathrm{~h}$ training sessions for a minimum of $12 \mathrm{~d}$ using an FR1 schedule of reinforcement with a 20 s timeout. In addition, some rats were yoked to the SA rats and received noncontingent infusions of cocaine (yoked-cocaine) or saline (yoked-saline) or received a program of noncontingent infusions based upon previous operant behavior from SA cocaine rats. $A$, Infusions of cocaine (200 $\mu \mathrm{g}$ cocaine/infusion) or saline across the last $12 \mathrm{~d}$ of self-administration. Active $(\boldsymbol{B})$ and inactive $(\boldsymbol{C})$ lever presses across the last $12 \mathrm{~d}$ of self-administration. $n=15$ yoked-saline; $n=15$ yoked-cocaine; $n=22 \mathrm{SA}$ cocaine.

average daily dose of cocaine treatment was $15.4 \pm 0.7$ and $15.4 \pm$ $0.8 \mathrm{mg} / \mathrm{kg}$ in the yoked-cocaine and cocaine self-administration groups, respectively (Table 1 ). In contrast, the average daily number of inactive lever presses remained static across treatment groups (Fig. 1).

Because it has been established previously that contingent cocaine administration produces more robust activation of the HPA axis than noncontingent exposure (Broadbear et al., 1999; Galici et al., 2000; Mantsch et al., 2007), we sought to verify this by assaying for differences in adrenal gland sizes at the end of the $14 \mathrm{~d}$ withdrawal period as a function of experimental treatment (also see data from Experiment 2, below). Adrenal gland hypertrophy is one of the hallmark signs of chronic HPA axis activation and is associated with elevated glucocorticoid secretion in rodents and humans (Rubin et al., 1987; Nemeroff et al., 1992; Ulrich-Lai et al., 2006; Anderson et al., 2014). One-way ANOVA as a function of treatment status revealed main effects for both adrenal weight $\left(F_{(2,51)}=4.3 ; p=0.02\right)$ and adrenal weight-tobody weight ratio $\left(F_{(2,51)}=4.7 ; p=0.01\right)$, with cocaine selfadministration rats showing selective increases in adrenal weight relative to both yoked-saline and yoked-cocaine groups $(p<0.05$ for each; Table 1).

Dendritic morphologic and spine density in $P L$

Given that a variety of repeated cocaine administration regimens induce structural modifications in prefrontal pyramidal neurons (Robinson and Kolb, 1999; Robinson et al., 2001; Shen et al., 2009; Gourley et al., 2012; Muñoz-Cuevas et al., 2013), we first examined the effects of 2 weeks of cocaine self-administration followed by a 2 week home cage withdrawal period on dendritic structural alterations in fluorescent-dye-labeled neurons in layers $2 / 3$ of PL (Fig. $2 A$ ).

One-way ANOVA revealed main effects for apical dendritic length $\left(F_{(2,18)}=4.6, p=0.03\right)$, with post hoc comparisons showing a statistically significant $16 \%$ decrease in the cocaine selfadministration group compared with yoked-saline rats $(p=$ 0.01 ) and a nonsignificant trend relative to the yoked-cocaine group (by $7.5 \%, p=0.08$; Fig. $2 B$ ). Analysis of apical dendritic length changes as a function of radial unit distance from neuronal perikarya (Sholl analysis) failed to reveal any region dependence of dendritic changes as a function of repeated cocaine treatment (data not shown). In contrast, noncontingent cocaine exposure, as assessed by the yoked-cocaine group, did not result in any significant reduction in apical dendritic length compared with yoked-saline rats $(p=0.2)$. No decreases in the number of branch endings on apical dendrites were evident after cocaine administration in either treatment group and basal dendrites
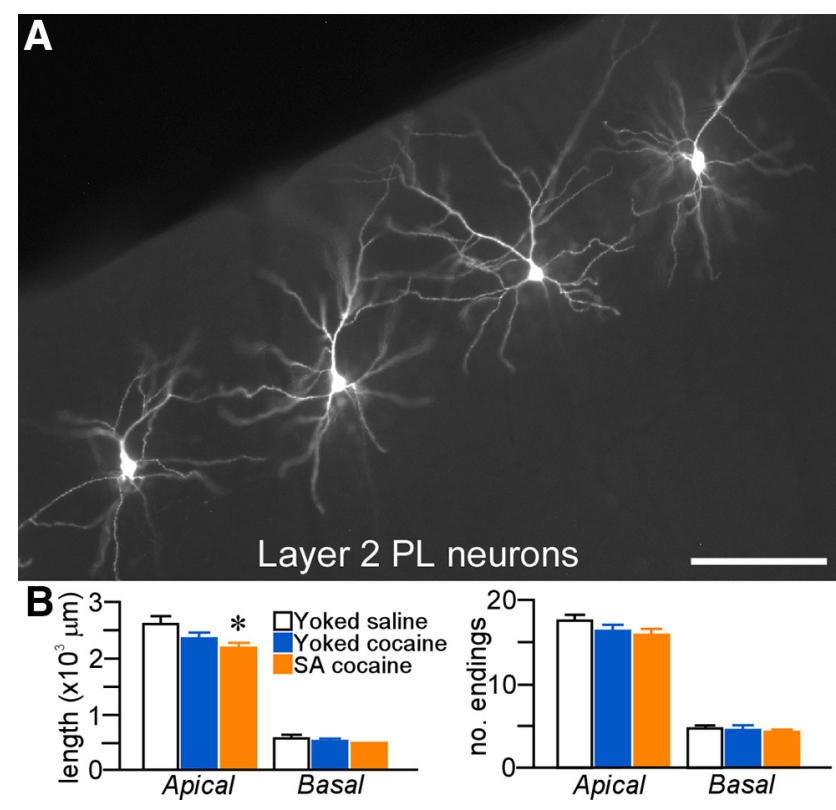

Figure 2. $\quad \boldsymbol{A}$, Epifluorescence photomicrograph depicting several layer 2 PL neurons that were dye injected with Lucifer yellow. Scale bar, $150 \mu \mathrm{m}$. B, Mean + SEM for dendritic length and number of branch endings for apical and basal dendrites as a function of treatment group. Downward trends were evident in both groups of rats receiving cocaine, although selfadministered (SA) cocaine rats showed the only significant decrease in apical dendritic length. $n=7$ ( 4.3 cells/rat) yoked-saline; $n=8$ ( 5.9 cells $/ \mathrm{rat}$ ) yoked-cocaine; $n=6$ (5.5 cells $/ \mathrm{rat}) \mathrm{SA}$ cocaine.

failed to demonstrate any sensitivity to repeated drug administration (Fig. 2B).

For the analysis of dendritic spine density as a function of treatment group, different subdivisions of the dendritic tree $(<150 \mu \mathrm{m}$ apical, $>150 \mu \mathrm{m}$ apical, $<150 \mu \mathrm{m}$ basal) were selected for highresolution confocal laser scanning microscopic imaging of dendritic segments across layers $2 / 3$ and layer 5 pyramidal neurons (Fig. $3 A, B)$. 3D digital renderings of dendritic segments were deconvolved, followed by the analysis of spine density and morphology using the semiautomated software NeuronStudio (Rodriguez et al., 2006; Radley et al., 2008; Fig. 3C). For this experiment, a combined total of 89,184 spines were analyzed (27,571 yoked-saline; 34,432 yoked-cocaine; 27,181 cocaine self-administration) from 227 neurons from layers $2 / 3$ and 5 of PL ( 74 yoked-saline; 86 yoked-cocaine; 67 cocaine self-administration).

Repeated cocaine self-administration induced decrements in overall (i.e., throughout apical and basal regions) dendritic spine 

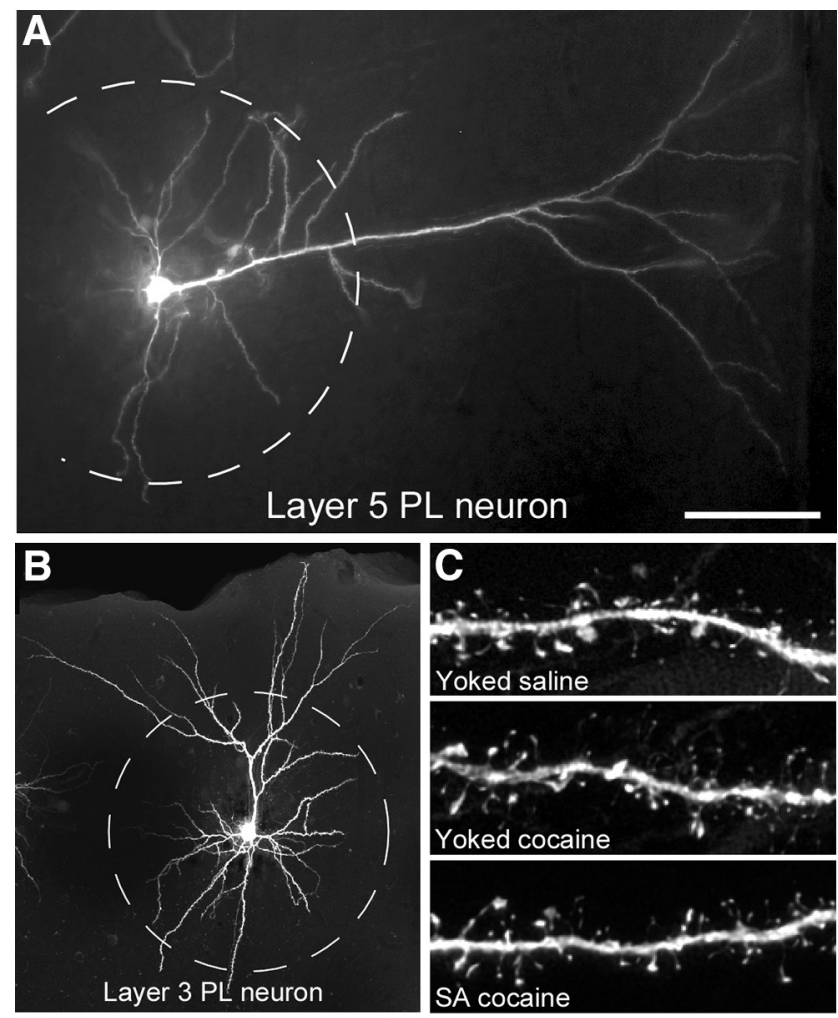

D

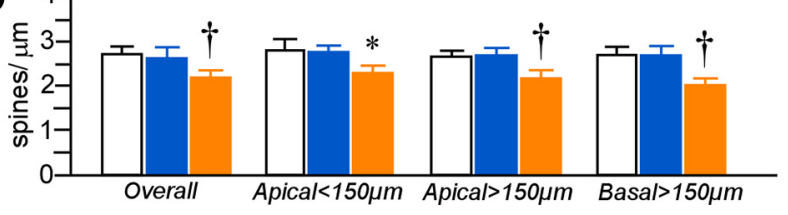

Figure 3. $\quad \boldsymbol{A}$, Epifluorescence photomicrograph depicting a deep layer $5 \mathrm{PL}$ neuron injected with fluorescent dye (Lucifer yellow). B, 3D digital reconstruction of a dye-filled layer $3 \mathrm{PL}$ neuron. The dashed lines in each image represent a radius of $150 \mu \mathrm{m}$ that was used to partition the apical dendritic tree for spine density quantification (i.e., proximally or distally) as a function of treatment group. C, High-resolution 3D digital images of deconvolved dendritic segments labeled with the fluorescent dye Lucifer yellow illustrating the anatomical detail for spine morphometric analyses. Scale bars: $\boldsymbol{A}, 150 \mu \mathrm{m} ; \boldsymbol{B}, 100 \mu \mathrm{m} ; \boldsymbol{C}, 10 \mu \mathrm{m}$. $\boldsymbol{D}$, Mean \pm SEM dendritic spine density in PL neurons as a function of treatment group. Self-administered (SA) cocaine rats showed selective decreases in spine density relative to both yoked groups. ${ }^{*} p<0.05$ relative to yoked-saline-treated group; $\uparrow p<0.05$ relative to yoked-saline and cocaine-treated groups. $n=11$ yoked-saline; $n=11$ yoked-cocaine; $n=12$ SA cocaine.

density in layers $2 / 3$ and 5 PL neurons $\left(F_{(2,31)}=3.7, p=0.04\right)$ that were most prominent in distal $(>150 \mu \mathrm{m})$ apical dendrites $\left(F_{(2,31)}=4.2, p=0.03\right)$ and basal dendrites $\left(F_{(2,31)}=4.2, p=\right.$ 0.03 ; Fig. $3 D)$. In post hoc comparisons, rats that selfadministered cocaine showed an attrition of overall spine density relative to both the yoked-saline (by 20\%, $p=0.02$ ) and yokedcocaine groups (by 18\%, $p=0.04$ ) and sustained comparable losses within distal apical and basal dendrites $(p<0.05$ for each). In contrast, yoked-cocaine administration was not found to result in any significant shifts in dendritic spine density at any region of the dendritic tree relative to the yokedsaline group.

Dendritic spine morphology in PL

Because evidence increasingly suggests that a standing population of thin spines in prefrontal cortical neurons may be important for optimal behavioral function (Arnsten et al., 2010; Dumitriu et al., 2010), our subsequent analysis of spines ex-
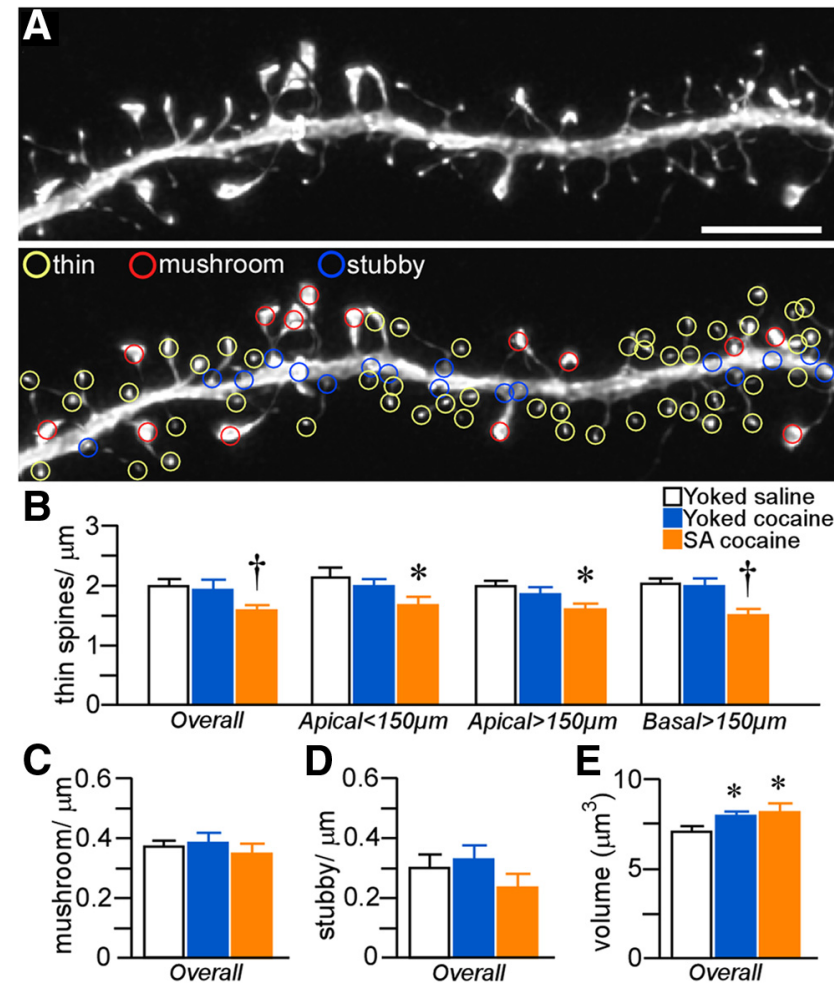

Figure 4. A, Example of high-resolution deconvolved optical z-stack of a dendritic segment used for spine analysis with NeuronStudio software. Open colored circles represent spine subtypes based upon user-defined parameters in the software. Scale bar, $5 \mu \mathrm{m}$. Histograms show cocaine treatment effects on thin $(\boldsymbol{B})$, mushroom $(\boldsymbol{C})$, and stubby $(\boldsymbol{D})$ spine density in pyramidal neurons in layers $2 / 3$ and 5 of PL. Thin spine subtypes are reliably decreased only in rats in the self-administered (SA) cocaine group. $\boldsymbol{E}$, Mean \pm SEM of spine volume as a function of treatment status. Cocaine administration (contingnent and noncontingent) produced generalized increases in this measure. ${ }^{*} p<0.05$ relative to yoked-saline group; $t p<0.05$ relative to yoked-saline and cocaine-treated groups. $n=11$ yoked-saline; $n=11$ yoked-cocaine; $n=12$, SA cocaine.

ploited the capabilities of NeuronStudio software to extract morphometric features of every spine quantified from the density analysis and then partitioned them into different functional subtypes (thin, mushroom, stubby; Fig. 4A). Analysis of spine subtype in across layers $2 / 3$ and 5 neurons in PL as a function of experimental treatment revealed a main effect on thin spine density $\left(F_{(2,31)}=5.7 ; p<0.01\right)$ and regional analyses highlighted prominent attrition within all dendritic compartments analyzed (proximal apical: $F_{(2,31)}=3.5, p=0.04$; distal apical: $F_{(2,31)}=4.6$, $p=0.02$; basal: $F_{(2,31)}=5.5 ; p<0.01$; Fig. $\left.4 B\right)$. Post hoc comparisons revealed decrements in overall thin spine density after cocaine self-administration compared with the yoked-saline $(22 \%$ decrease, $p<0.01)$ and yoked-cocaine (17\% decrease, $p=0.02$ ) rats. In contrast, neither mushroom nor stubby spine subtypes were affected after either means of chronic cocaine administration (Fig. 4C,D)

To provide additional information about the effects of chronic cocaine administration on spine morphology in PL pyramidal neurons, we analyzed morphometric parameters regardless of subtype. For this analysis, we focused on spine volume because electron microscopic evidence has identified a strong correlation among spine volume, postsynaptic density area, and the number of presynaptic vesicles (Harris and Stevens, 1989; Knott et al., 2006). This analysis uncovered main effects for spine volume $\left(F_{(2,31)}=7.4, p<0.01\right)$. Strikingly, generalized increases in spine volume were revealed in noncontingent and contingent cocaine groups compared with yoked-saline 
A
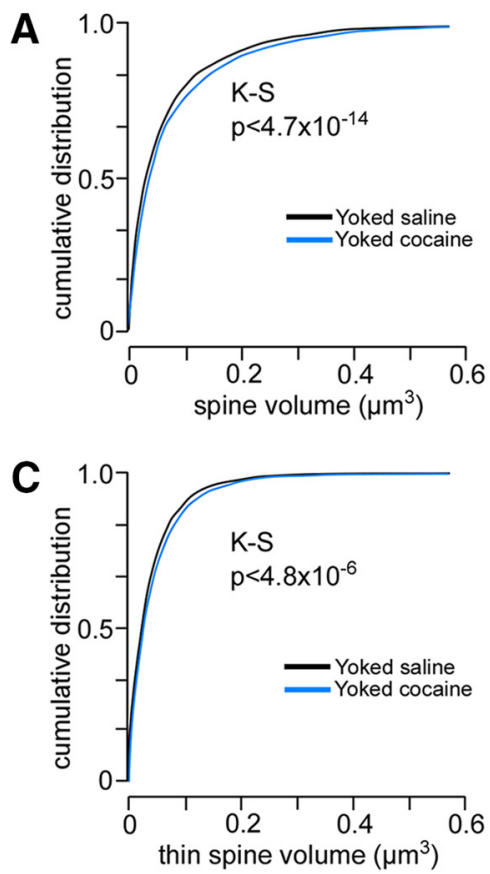

E

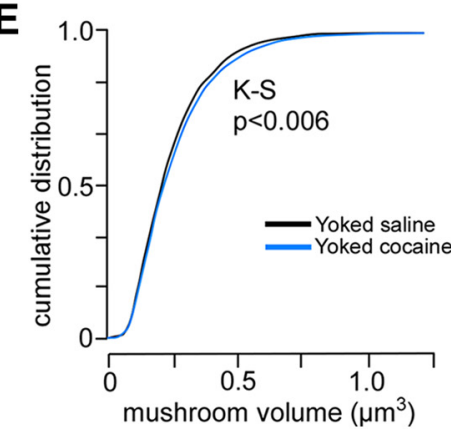

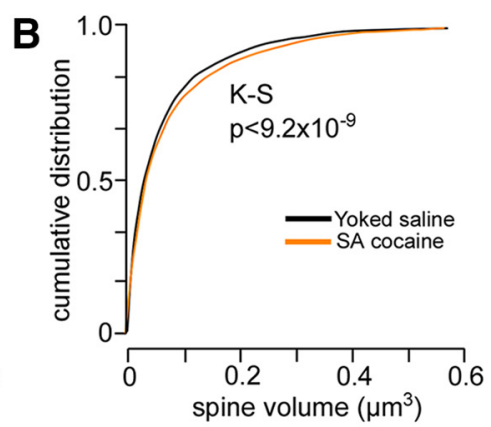

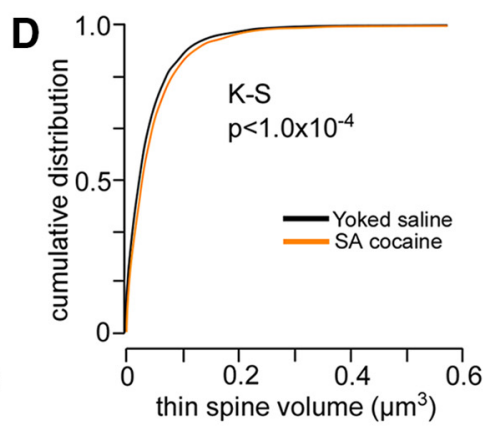

$\mathbf{F}$

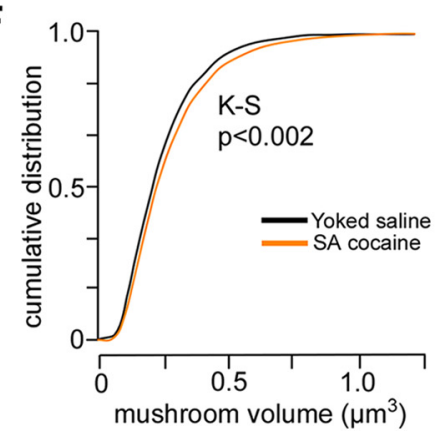

Figure 5. $\boldsymbol{A}-\boldsymbol{C}$, Cumulative frequency distributions of spine volumes in $\mathrm{PL}$ neurons as a function of experimental treatment. Comparisons are made between yoked-saline and yoked-cocaine groups $(\boldsymbol{A}, \boldsymbol{C}, \boldsymbol{E})$ and yoked-saline and self-administration cocaine $(\boldsymbol{B}, \boldsymbol{D}, \boldsymbol{F})$. Each treatment results in a generalized rightward shift (i.e., increase) in spine volume regardless of cocaine treatment group, suggesting a mechanism leading to enlargement of spines relative to both forms of chronic cocaine administration. Rows show pairwise comparisons of distributions for the total $(\boldsymbol{A}, \boldsymbol{B})$, thin $(\boldsymbol{C}, \boldsymbol{D})$, and mushroom $(\boldsymbol{E}, \boldsymbol{F})$ spine population. K-S, Kolmogorov-Smirnov test.

groups ( $p<0.05$ for each; Fig. $4 E$ ), and cumulative frequency analyses verified that group differences were due to upward shifts throughout the population (Fig. 5). Collectively, these data suggest that cocaine-induced increases in dendritic spine volume are dissociable from the attrition of thin spines after chronic drug self-administration.

\section{Generality of repeated cocaine administration effects to other} cortical structures

Ancillary analyses were performed in a subset of rats to examine the impact of repeated cocaine administration on dendritic spine density in other cortical subfields within the frontal pole. Because previous studies have shown that repeated psychostimulant treatment is capable of inducing dendritic spine loss in LO pyramidal neurons (Robinson and Kolb, 1999; Crombag et al., 2005; Gourley et al., 2012), we subjected a subset of rats used in the analysis of PL for dye filling of neurons in LO (Fig. 6A). An additional group of cells were loaded in the motor cortex (M1-2 regions) to serve as a possible negative control region relative to putative widespread effects throughout prefrontal regions (Fig. $6 B)$. Main effects were observed as a function of treatment group
$\left(F_{(2,10)}=30.5 ; p<0.001\right)$, with selfadministration cocaine rats showing an $18 \%$ decrement in spine density in LO neurons relative to both yoked counterparts ( $p<0.05$ for each comparison; Fig. $6 C)$. In contrast, M1-2 pyramidal neurons failed to show any differences in spine density as a function of treatment $\left(F_{(2,10)}=0.3 ; p=0.8\right.$; Fig. $\left.6 D\right)$.

Spine morphologic analyses in LO neurons revealed a similar pattern of regressive plasticity as PL after chronic cocaine administration. A main effect was observed for spine density in LO neurons as a function of treatment $\left(F_{(2,10)}=13.4\right.$; $p=0.001)$, with a $17 \%$ decrease in selfadministration rats relative to both yoked counterparts ( $p<0.05$ for each comparison). Main effects of cocaine treatment were also evident on other spine subtypes in LO neurons (mushroom: $F_{(2,10)}=6.3$, $p=0.02$; stubby: $F_{(2,10)}=6.7, p=0.01$; Fig. $6 C$ ). In contrast, examination of spine subtypes in M1-2 neurons failed to reveal any trends or main effects (thin: $F_{(2,10)}=$ $0.3, p=0.7$; mushroom: $F_{(2,10)}=2.4, p=$ 0.2 ; stubby: $F_{(2,10)}=0.5, p=0.6$; Fig. $\left.6 D\right)$.

\section{Selectivity of cocaine contingency effects on PL structural plasticity} Our data suggest that repeated cocaine administration decreases structural indices in $\mathrm{mPFC}$ pyramidal neurons, but also is dependent on the contingency of drug treatment. Based upon this potential disparity with previous work, we examined the possibility that cocaine selfadministration effects on structural plasticity in mPFC may be accounted for by drug or learning effects alone. Therefore, in one follow-up experiment, we analyzed the same dendritic and spine morphologic endpoints in layer $2 / 3 \mathrm{PL}$ neurons using a drug administration protocol that has been previously documented in the literature (daily injections of cocaine for 4 weeks, followed by a 4-week recovery period; Robinson and Kolb, 1999; Dumitriu et al., 2012). However, these analyses failed to reveal any main effects of noncontingent cocaine exposure on any index of structural plasticity (Fig. 7). In another experiment, rats were trained in a food self-administration learning task that contained a contingency schedule and duration that paralleled cocaine self-administration and this also failed to alter structural plasticity in PL pyramidal neurons (Fig. 8). Collectively, these data endorse the interpretation from the foregoing experiment that the combination of both repeated cocaine administration and contingency of that administration are necessary for the induction of regressive structural modifications in PL neurons.

\section{Cocaine self-administration increases adrenocortical output and impairs working memory}

Adrenocortical activation

Previous evidence suggests that contingent cocaine administration produces more robust activation of the HPA axis than 

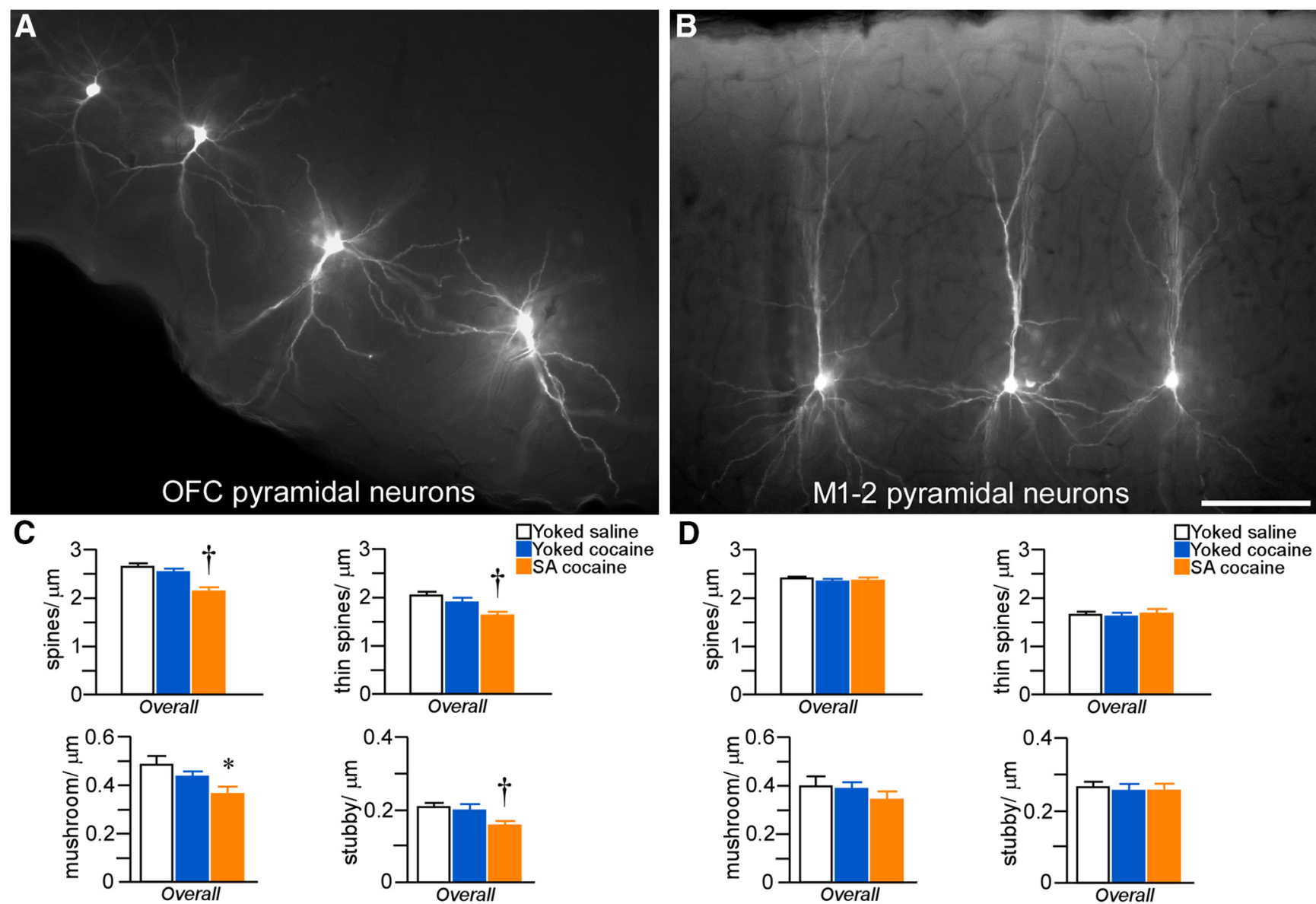

Figure 6. $A, B$, Epifluorescence photomicrographs depicting several pyramidal neurons filled with Lucifer yellow in the L0 and M1-2. Scale bar, $100 \mu \mathrm{m}$. C, Mean \pm SEM dendritic spine and subtype densities in $\mathrm{L} 0$ neurons as a function of treatment group. Self-administered $(S A)$ cocaine rats showed generalized decreases in spine density and subtypes compared with yoked counterparts. ${ }^{*} p<0.05$ relative to yoked-saline group; $t p<0.05$ relative to yoked-saline and cocaine-treated groups. $n=3$ yoked-saline; $n=5$ yoked-cocaine; $n=5$ SA cocaine. $D$, Mean \pm SEM dendritic spine and subtype densities in M1-2 neurons as a function of treatment group. $n=3$ yoked-saline; $n=3$ yoked-cocaine; $n=5$ SA cocaine.

noncontingent exposure (Broadbear et al., 1999; Galici et al., 2000; Mantsch et al., 2007). In the first experiment, we identified gross alterations in adrenal hypertrophy after repeated cocaine self-administration that raise the possibility that longterm effects of repeated cocaine self-administration may be accompanied by augmented HPA activity. Therefore, we undertook additional experiments to address a more direct functional evidence for elevated HPA output over the course of the $14 \mathrm{~d}$ of cocaine treatment. To this end, repeated sampling of blood was collected from the tail vein from all groups of rats on days 1 and 12 of training sessions to assay for changes in adrenocortical output. Operant behavior and drug infusion data from this cohort of rats are shown in Figure 9. Baseline blood samples were collected immediately before the $2 \mathrm{~h}$ drug administration session (no samples were taken during drug treatment to avoid disrupting performance during the task) and immediately afterward in $30 \mathrm{~min}$ intervals (Fig. 10). Only rats from which we were able to successfully collect blood samples at every time point throughout the course of the experiment (yoked-saline $=5$; yoked-cocaine $=5$; self-administration $=7$ ) were included in the analysis. Furthermore, because yoked-saline rats did not show any adrenocortical activation as a function of operant chamber exposure on day 1 of the operant training task (data not shown), they were excluded from the statistical analysis. Principal comparisons en- tailed two within-subjects factors (comparing plasma corticosterone levels as a function of time interval of blood sampling within days 1 and 14 and comparing differences across these $2 \mathrm{~d}$ of sampling) and 1 between-subjects factor (yoked-cocaine vs cocaine self-administration).

Repeated-measures ANOVA revealed main effects for the within-subjects measure of time interval within each day $\left(F_{(3,30)}=\right.$ 6.49, $p<0.01)$ and the interaction between the experimental treatment as a function of day of drug treatment $\left(F_{(1,10)}=11.00\right.$, $p<0.01)$. Both groups of rats displayed comparable baseline levels and increases in plasma corticosterone titers in the aftermath of cocaine treatment on day 1 and baseline levels on day 12 , whereas rats that self-administered cocaine continued to show enhanced adrenocortical output on the final day of selfadministration compared with yoked-cocaine rats (Fig. 10A). Comparison of integrated corticosterone levels on days 1 and 12 highlight the interaction between treatment effects that develop over the course of repeated cocaine self-administration (Fig. 10B) such that rats self-administering cocaine failed to show response decrements in adrenocortical output relative to yoked-cocaine rats.

\section{Working memory}

After 2 weeks of cocaine administration and a 2 week withdrawal period (i.e., to match our experimental design for the analysis of dendritic spines in PL), rats were trained in a delayed alternation 

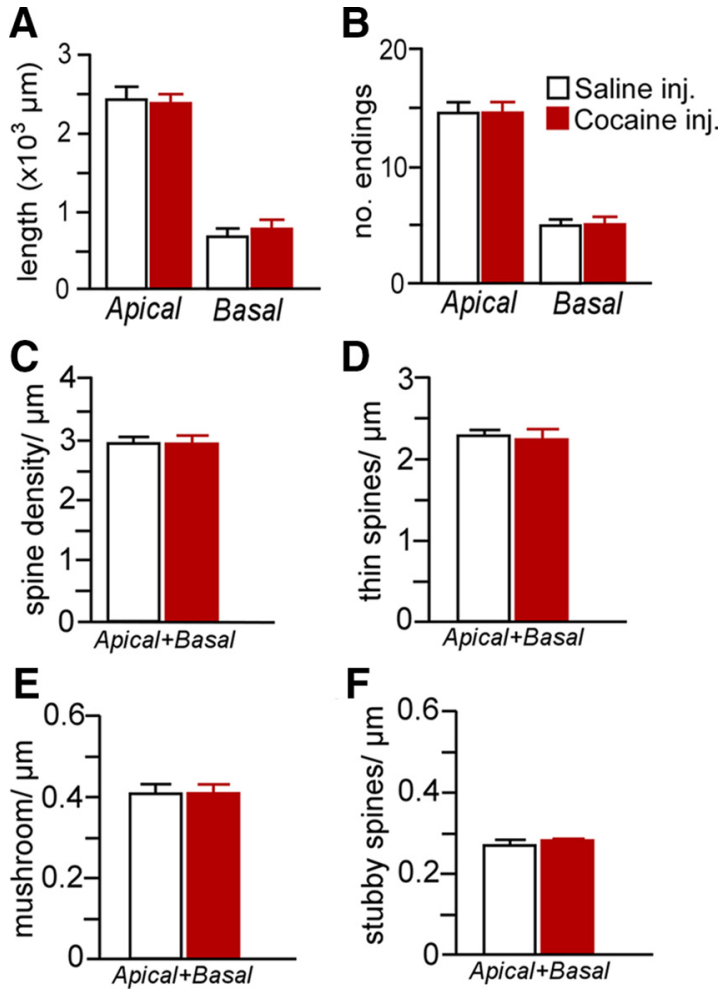

Figure 7. Mean \pm SEM for dendritic length $(\boldsymbol{A})$ and number of branch endings $(\boldsymbol{B})$ after either 4 weeks of repeated cocaine ( $15 \mathrm{mg} / \mathrm{kg}$, i.p.) or saline injections ( $5 \mathrm{~d} /$ week, followed by a 4-week recovery period). Mean \pm SEM for overall $(\boldsymbol{C})$, thin $(\boldsymbol{D})$, mushroom $(\boldsymbol{E})$, and stubby $(\boldsymbol{F})$ spine densities as a function of cocaine or saline injections. This regimen of chronic cocaine administration failed to produce any frank differences in any of the dendritic or spine morphologic indices examined in PL neurons. $n=4$ saline injection; $n=7$ cocaine injection, $n=6-8$ neurons/rat.

task using a T-maze. This task has been shown to be dependent upon intact mPFC functioning (Divac, 1971; Ramos et al., 2003) and reveals behavioral impairments that are associated with dendritic atrophy and thin dendritic spine loss in PL neurons (Hains et al., 2009; Anderson et al., 2014). The number of training sessions (i.e., days) required for groups of rats to reach an equivalent level of performance was used as a measure of acquisition (i.e., $80 \%$ choice accuracy at a 15 s delay; Ramos et al., 2003) and was not found to be significant $\left(F_{(2,18)}=3.14, p=0.07\right.$; Fig. $\left.11 \mathrm{~A}\right)$. Repeated-measures ANOVA revealed main effects for delay interval $\left(F_{(2,36)}=67.18, p<0.01\right)$, treatment group $\left(F_{(2,18)}=9.51, p<\right.$ $0.01)$, and interaction of delay interval as a function of treatment group $\left(F_{(4,18)}=2.73, p=0.04\right)$. Cocaine self-administration rats displayed impairments in delayed alternation relative to the yoked-saline and yoked-cocaine groups at $30 \mathrm{~s}(p<0.01$ and $p=$ 0.01 , respectively; Fig. $11 B$ ). At the 60 s delay interval, alternation deficits were enhanced after cocaine self-administration relative to yoked-saline controls $(p<0.01)$; however, these were not significantly different from yoked-cocaine rats $(p=0.3)$. In addition, at the $60 \mathrm{~s}$ delay, yoked-cocaine rats displayed a nonsignificant trend toward impaired performance relative to yokedsaline rats $(p=0.07)$.

\section{Discussion}

The present study extends previous work seeking to understand the effects of chronic cocaine administration on structural plasticity in $\mathrm{mPFC}$, a critical region involved in driving relapse to cocaine-seeking behavior (McFarland and Kalivas, 2001; Stefanik
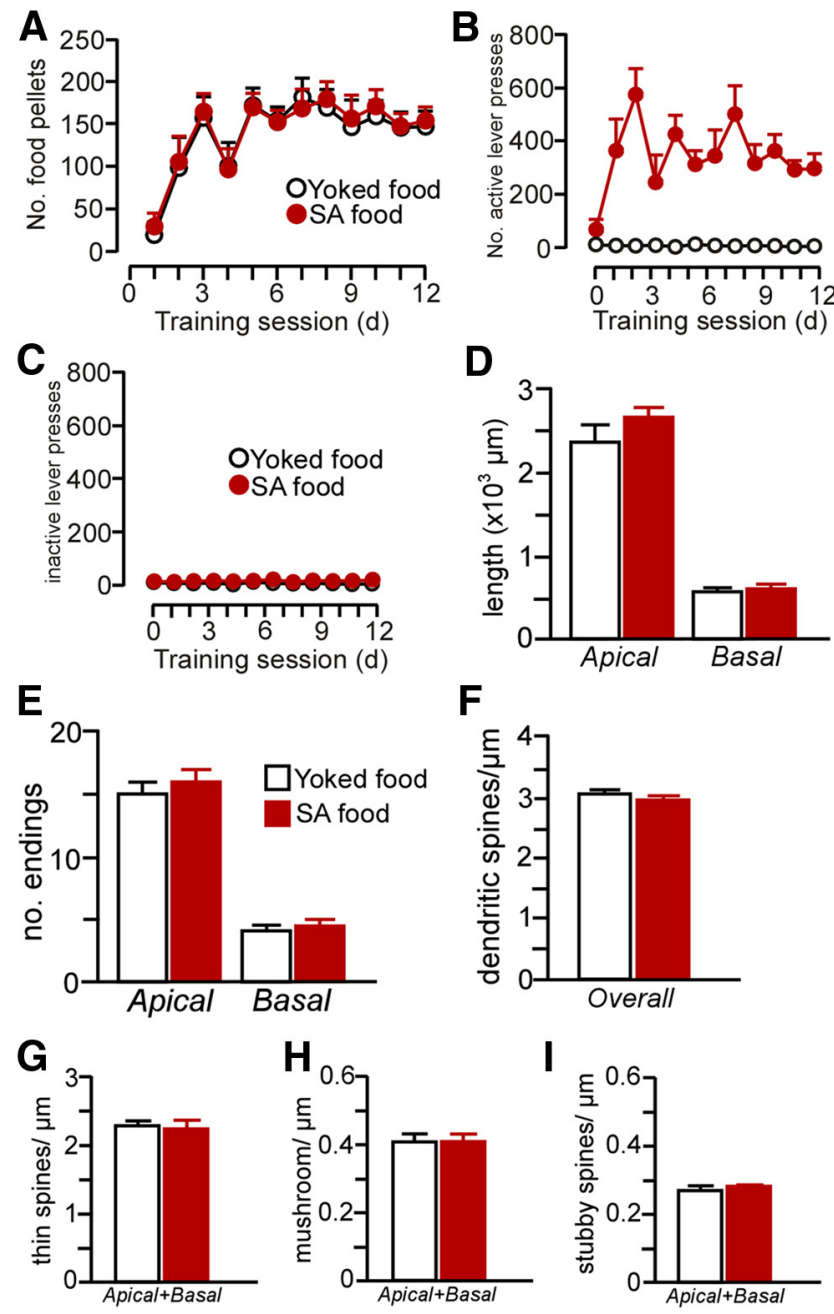

Figure 8. Rats underwent food self-administration (SA food) using the same procedures as with cocaine self-administration (FR1 schedule of reinforcement with a $20 \mathrm{~s}$ timeout) in $2 \mathrm{~h}$ sessions daily for a minimum of $12 \mathrm{~d}$. In addition, some rats (yoked-food) received noncontingent food pellets in a manner yoked to the SA food rats. $A$, Number of food pellets received across the last $12 \mathrm{~d}$ of food self-administration. $\boldsymbol{B}, \boldsymbol{C}$, Number of active and inactive lever presses across the last $12 \mathrm{~d}$ of food self-administration. $\boldsymbol{D}-\boldsymbol{I}$, Food self-administration did not result in any changes in dendritic $(\boldsymbol{D}, \boldsymbol{E})$ or spine morphology $(\boldsymbol{F}-\boldsymbol{I})$ in PL neurons. This suggests that reinforcement or contextual aspects of the learning procedure per se are not sufficient for the induction of prefrontal structural plasticity. $n=5$ yoked-food; $n=6$ self-administration food $n=6-7$ neurons/rat.

et al., 2013). Although we verified that repeated cocaine selfadministration produces altered structural and functional plasticity in mPFC neurons, this contrasted with previous work showing increases in dendritic branching and spine density after similar drug treatments. Instead, we found cocaine-induced structural deficits in PL pyramidal neurons that were distinguished by decreased apical dendritic length and overall reductions in dendritic spine density, most notably within thin spine subtypes. In a further departure from previous work, evidence for mPFC structural reorganization was lacking in rats that received noncontingent cocaine (i.e., either via intravenous yoked procedures or intraperitoneal experimenter administration), with the exception that spine volumes were increased in both yokedcocaine and self-administration groups. Examination of PLdependent spatial working memory revealed decrements in performance that were more prominent in rats that received contingent cocaine and paralleled dendritic spine deficits observed in 

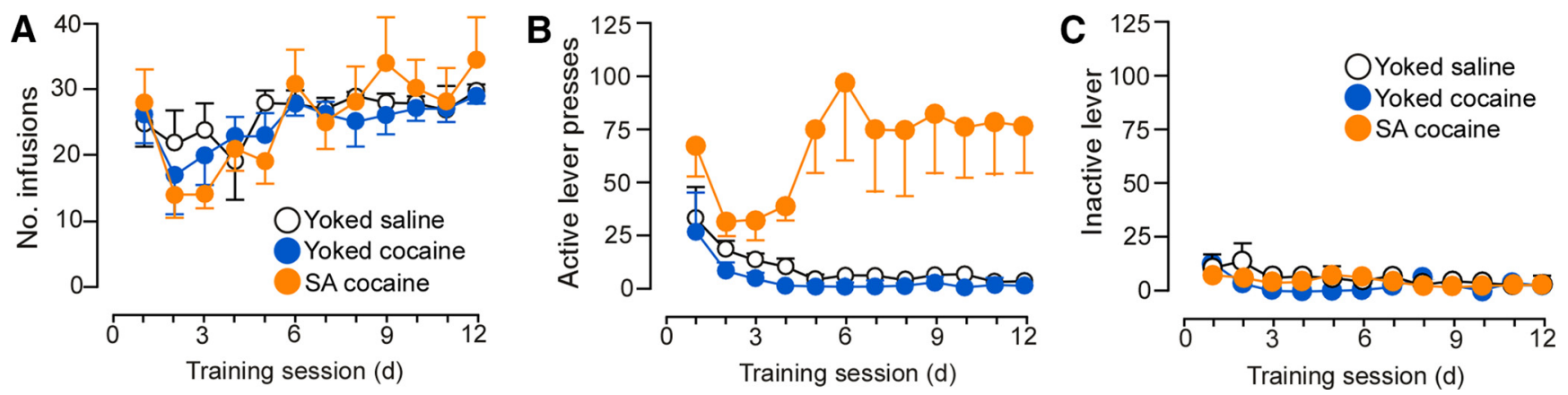

Figure 9. Line graphs displaying operant and infusion data from rats submitted to repeated blood sampling and behavioral testing. $A$, Rats received infusions of cocaine (200 $\mu \mathrm{g}$ cocaine/ infusion) or saline across the last $12 \mathrm{~d}$ of self-administration. Graphs in middle $(\boldsymbol{B})$ and right $(\boldsymbol{C})$ depict active and inactive lever presses, respectively. $n=7$ yoked-saline; $n=10$ yoke cocaine; $n=$ $11 \mathrm{SA}$ cocaine.

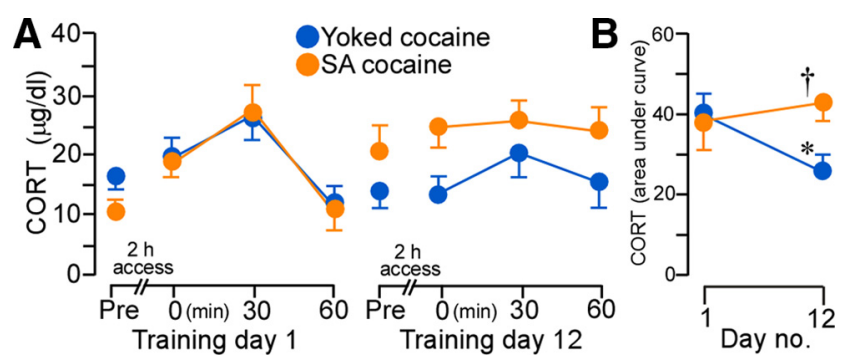

Figure 10. $A$, Mean \pm SEM plasma corticosterone (CORT) levels in rats at various time points before and after cocaine administration on day 1 (left) and day 12 (right). B, Whereas CORT values increased in both yoked and self-administration $(S A)$ cocaine groups on day $1, S A$ cocaine rats continued to show elevated responses on the last day of drug administration. ${ }^{*} p<0.05$, significantly different from day 1 of drug treatment; $\uparrow p<0.05$, significantly different from yoked-cocaine group. $n=5$ yoked-cocaine; $n=7 \mathrm{SA}$ cocaine.
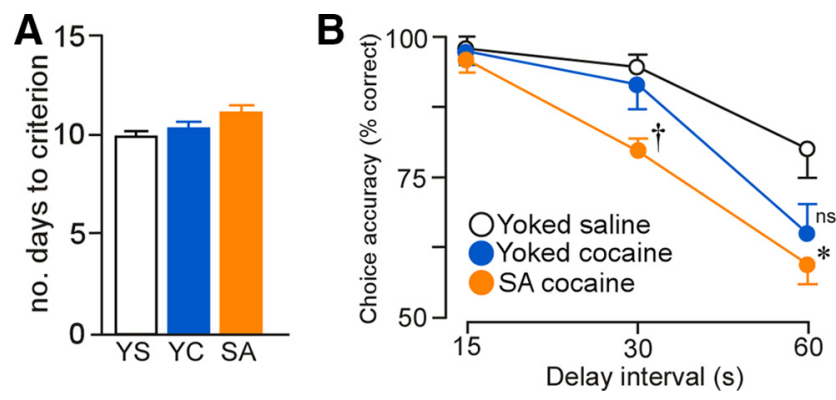

Figure 11. A, Histogram representing the average number of days required to reach an equivalent level of performance in the delayed alternation task ( $>80 \%$ choice accuracy). $\boldsymbol{B}$, Mean \pm SEM for the percentage of correct responses as a function of delay interval and experimental treatment. Self-administered (SA) cocaine-treated rats displayed significant decreases task performance at the $30 \mathrm{~s}$ delay interval relative to both yoked groups, whereas decrements at $60 s$ in the $S A$ cocaine group were significantly decreased only compared with yoked-saline (YS) controls. ${ }^{*} p<0.05$ relative to YS group; $\uparrow p<0.05$ relative to YS and yoked-cocaine (YC) groups. $n=7 \mathrm{YS} ; n=10, \mathrm{YC} ; n=11 \mathrm{SA}$ cocaine.

this same region. Follow-up experiments failed to demonstrate any effects of food self-administration on structural alterations in PL neurons. Consistent with previous evidence supporting a link between the contingency of cocaine administration and the degree of HPA axis engagement, the present study also found that cocaine self-administration produced increased adrenocortical responses on the first and last day of the 2 week session of treatment and adrenal hypertrophy at the end of the withdrawal period. Whereas elevated plasma levels of glucocorticoids have been shown to facilitate both the behavioral and reinforcing effects of cocaine (Deroche et al., 1997; Marinelli et al., 1997; Goeders, 2002; Mantsch et al., 2007; Burke and Miczek, 2014), our data shed new light on a possible relationship between increased glucocorticoids and mPFC impairment after cocaine self-administration.

\section{Methodological considerations}

In contrast to our present findings, previous studies examining the effects of psychostimulant administration on structural plasticity in mPFC have reported increases in dendritic branching and spine density in PL neurons. Whereas much of this evidence is derived from the analysis of spines and dendrites in Golgistained preparations (Robinson and Kolb, 1999; Robinson et al., 2001; Muñoz-Cuevas et al., 2013), data gathered from 3D electron microscopic and confocal analyses show that the Golgi technique undersamples dendritic spine density by $65-75 \%$ and is biased against thin subtypes (Shen et al., 2009; Dumitriu et al., 2012). Another consideration is that our spine morphology analysis revealed that both noncontingent and contingent cocaine administration increased spine volume across all three subtypes examined. Therefore, it is possible that the enlargement of $\mathrm{mPFC}$ spines, particularly in thin subtypes (Fig. $5 C, D$ ), in response to psychostimulant treatment could improve their detection in lower-resolution microscopic approaches, leading to spurious results. In addition, our observation of decreases in dendritic spine density in PL neurons may offer a better parallel accounting for deficits in working memory seen in rats after cocaine selfadministration and suggests a more plausible, albeit distinct, set of cellular mechanisms (i.e., regressive instead of growth-like changes) accounting for medial prefrontal impairment in cocaine addiction.

The observation that cocaine may induce regressive structural alterations (e.g., dendritic spine loss) in prefrontal neurons in the rodent brain is not without precedent, although this phenomenon has been considered previously to be exclusive to LO (Robinson and Kolb, 2004; DePoy and Gourley, 2015). Although these cortical fields are considered complementary elements within a prefrontal network, LO is both functionally and anatomically differentiated from mPFC and is implicated in different aspects of cocaine addiction (Goldstein and Volkow, 2011; Pelloux et al., 2013; Lucantonio et al., 2014; DePoy and Gourley, 2015). Whereas our examination of LO generally corroborates previous work showing that pyramidal neurons in this region display decrements in dendritic spine density after repeated cocaine treatment, it is noteworthy that these effects were found to be largely exclusive to the self-administration group. 


\section{Role of PL in HPA axis alterations after cocaine self-administration}

The mPFC comprises part of a limbic forebrain network of cell groups with the capacity to inhibit stress-induced HPA activation (for recent reviews, see Ulrich-Lai and Herman, 2009; Radley et al., 2015). HPA-inhibitory influences from mPFC are imparted via stress activation of a subpopulation of PL neurons that projects to a GABAergic relay within the bed nuclei of the stria terminalis, which in turn issues projections to HPA effectors in the paraventricular nucleus of the hypothalamus (Cullinan et al., 1993; Diorio et al., 1993; Figueiredo et al., 2003; Choi et al., 2007; Radley et al., 2009). Synaptic compromise and diminished activation within this circuit is associated with elevated HPA activity after chronic stress (Radley et al., 2013), raising the possibility that repeated cocaine self-administration may further compromise prefrontal HPA-inhibitory mechanisms in part via a glucocorticoid-dependent mechanism. Along these lines, rats that chronically self-administer cocaine show increased HPA axis sensitization and disruptions in glucocorticoid receptormediated feedback (Mantsch et al., 2007). Considering the importance of PL in regulating HPA activity (Diorio et al., 1993; Figueiredo et al., 2003; Radley et al., 2009), its structural susceptibility to adrenocortical hormones (Wellman, 2001; Cerqueira et al., 2007; Anderson et al., 2014), and its role in driving relapse to cocaine seeking (McFarland and Kalivas, 2001; LaLumiere and Kalivas, 2008; Stefanik et al., 2013), an important next step will be to examine carefully the glucocorticoid dependency of the adverse structural and functional changes in this region resulting from repeated cocaine use.

\section{Disparities in adrenocortical activation after contingent and noncontingent cocaine administration}

Upon first glance, the results observed with adrenocortical activation may appear surprising because it might be argued that yoked-cocaine administration should be more stressful compared with cocaine self-administration. Two studies have shown that exposure to noncontingent cocaine is more aversive or anxiogenic than contingent administration (Palamarchouk et al., 2009; Twining et al., 2009), whereas a substantial amount of evidence indicates that cocaine, whether given in a contingent or noncontingent manner, has both rewarding and aversive effects (Ettenberg, 2004). However, two points must be considered here. First, increased HPA activity associated with prolonged cocaine self-administration is not equivalent to "chronic stress." A more likely explanation for this verisimilitude is that prolonged cocaine self-administration produces a similar set of neuroadaptations in common neural pathways as chronic stress exposure. These include, but are not limited to, alterations in HPA function, but also prominently feature changes in neural systems mediated by central norepinephrine and extrahypothalamic corticotropin-releasing factor (Rassnick et al., 1993; Sarnyai et al., 1995; Erb et al., 1998; Delfs et al., 2000; Erb et al., 2000; Mantsch et al., 2010).

Second, although a complex relationship exists between HPA axis alterations and human cocaine addiction, most studies have observed that cocaine administration increases cortisol levels in cocaine addicts and individuals with no previous history of cocaine use (Mendelson et al., 1992; cf. Vescovi et al., 1992; Baumann et al., 1995; Heesch et al., 1995). Evidence from several laboratory animal species shows robust HPA axis induction in response to contingent and noncontingent cocaine administration (Moldow and Fischman, 1987; Saphier et al., 1993; Broadbear et al., 1999; Galici et al., 2000). Intriguingly, two separate reports in rats and macaque monkeys showed that acute cocaine self-administration produced a greater degree of HPA activation than yoked-cocaine counterparts (Broadbear et al., 1999; Galici et al., 2000). Nevertheless, our results speak more to the possibility that prolonged cocaine self-administration is accompanied by a persistent elevation in adrenocortical activity (i.e., increased corticosterone, adrenal hypertrophy) relative to noncontingent exposure and suggest that both the reward contingencies and the physiological effects of cocaine are involved in maintained elevation of HPA activity.

One possible explanation for the maintenance of adrenocortical activation after cocaine self-administration is that the observed dendritic spine impairments in PL reflect a disruption in its capacity to inhibit the HPA axis. Given the high degree of sensitivity of the prefrontal cortex to environmental and biologic factors such as stress, aging, and mental illness (for review, see Arnsten et al., 2010), cocaine self-administration could induce regressive structural plasticity in PL in which HPA axis perturbations are a secondary consequence.

Although this does not account for how contingent, but not noncontingent, cocaine administration produces PL impairments in the first place, it relates to an extensive literature implicating $\mathrm{mPFC}$ an interface for regulating the interaction between conditioned cocaine reward and the stress response (Goeders et al., 2014) and is consistent with prior work indicating that changes in PL-based circuits occur in drug self-administering, but not yoked-drug, rats (McFarland et al., 2003; LaLumiere and Kalivas, 2008).

\section{Functional considerations}

Dendritic spines are labile structures that are highly sensitive to a variety of environmental and physiological stimuli (Yuste and Bonhoeffer, 2001; Nimchinsky et al., 2002; Kirov et al., 2004; Holtmaat et al., 2005; Liston et al., 2013). Changes in dendritic spine number and architecture have been increasingly shown to provide a structural basis for understanding prefrontal-related memory functions, with optimal functioning requiring a standing population of thin spines in pyramidal neurons (Hains et al., 2009; Arnsten et al., 2010; Dumitriu et al., 2010; Anderson et al., 2014). Our results are consistent with this idea because thin spine loss was associated with working memory impairments in cocaine self-administration rats. However, the fact that increases in dendritic spine volume in PL neurons were evident after cocaine selfadministration and noncontingent exposure raises questions as to whether such alterations may also contribute to prefrontal impairment. For example, one report recently correlated increased volume of thin spines in prefrontal pyramidal neurons with cognitive impairment (Dumitriu et al., 2010), suggesting that this structural alteration may also contributing to impairment in working memory. However, one caveat in our interpretation is that we did not compare directly dendritic spine alterations in PL and working memory function in individual rats after cocaine administration because acquisition of the learning task itself could influence dendritic spine numbers or morphology and confound our interpretation. At a minimum, these studies shed light on the relationship between the structural synaptic changes that may underlie prefrontal impairments in drug addiction models for future consideration.

Our finding that cocaine self-administration induced selective effects in PL structural plasticity and corresponding working memory impairments is consistent with impaired prefrontal functioning observed in humans after cocaine use. Imaging stud- 
ies have found decrements in prefrontal gray matter volume and reduced activity during inhibitory control tasks in cocaine addicts (Goldstein and Volkow, 2011). Moreover, cocaine addicts display behaviors indicative of prefrontal dysfunction, such as inhibitory control deficits, that bear similarities to perseveration of drug seeking (Kaufman et al., 2003; Hester and Garavan, 2004). Similarly, in rats, cocaine self-administration decreases neuronal excitability and plasticity in the PL region (Sun and Rebec, 2006; Whitfield et al., 2011; Chen et al., 2013) and produces deficits in prefrontal-dependent tasks (George et al., 2008; Sudai et al., 2011). These data suggest that regressive synaptic plasticity in $\mathrm{mPFC}$ neurons may be indicative of a more generalized set of broad effects on a prefrontal network that are produced by repeated cocaine self-administration, contributing to disordered thought and behavior underlying prefrontal impairment in cocaine addiction.

\section{References}

Anderson RM, Birnie AK, Koblesky NK, Romig-Martin SA, Radley JJ (2014) Adrenocortical status predicts the degree of age-related deficits in prefrontal structural plasticity and working memory. J Neurosci 34:83878397. CrossRef Medline

Arnsten AF, Paspalas CD, Gamo NJ, Yang Y, Wang M (2010) Dynamic network connectivity: a new form of neuroplasticity. Trends Cogn Sci 14:365-375. CrossRef Medline

Baumann MH, Gendron TM, Becketts KM, Henningfield JE, Gorelick DA, Rothman RB (1995) Effects of intravenous cocaine on plasma cortisol and prolactin in human cocaine abusers. Biol Psychiatry 38:751-755. CrossRef Medline

Broadbear JH, Winger G, Cicero TJ, Woods JH (1999) Effects of response contingent and noncontingent cocaine injection on hypothalamicpituitary-adrenal activity in rhesus monkeys. J Pharmacol Exp Ther 290: 393-402. Medline

Burke AR, Miczek KA (2014) Stress in adolescence and drugs of abuse in rodent models: role of dopamine, CRF, and HPA axis. Psychopharmacology 231:1557-1580. CrossRef Medline

Cerqueira JJ, Taipa R, Uylings HB, Almeida OF, Sousa N (2007) Specific configuration of dendritic degeneration in pyramidal neurons of the medial prefrontal cortex induced by differing corticosteroid regimens. Cereb Cortex 17:1998-2006. CrossRef Medline

Chen BT, Yau HJ, Hatch C, Kusumoto-Yoshida I, Cho SL, Hopf FW, Bonci A (2013) Rescuing cocaine-induced prefrontal cortex hypoactivity prevents compulsive cocaine seeking. Nature 496:359-362. CrossRef Medline

Choi DC, Furay AR, Evanson NK, Ostrander MM, Ulrich-Lai YM, Herman JP (2007) Bed nucleus of the stria terminalis subregions differentially regulate hypothalamic-pituitary-adrenal axis activity: implications for the integration of limbic inputs. J Neurosci 27:2025-2034. CrossRef Medline

Crombag HS, Gorny G, Li Y, Kolb B, Robinson TE (2005) Opposite effects of amphetamine self-administration experience on dendritic spines in the medial and orbital prefrontal cortex. Cereb Cortex 15:341-348. Medline

Cullinan WE, Herman JP, Watson SJ (1993) Ventral subicular interaction with the hypothalamic paraventricular nucleus: evidence for a relay in the bed nucleus of the stria terminalis. J Comp Neurol 332:1-20. CrossRef Medline

Delfs JM, Zhu Y, Druhan JP, Aston-Jones G (2000) Noradrenaline in the ventral forebrain is critical for opiate withdrawal-induced aversion. Nature 403:430-434. CrossRef Medline

DePoy LM, Gourley SL (2015) Synaptic cytoskeletal plasticity in the prefrontal cortex following psychostimulant exposure. Traffic. In press.

Deroche V, Marinelli M, Le Moal M, Piazza PV (1997) Glucocorticoids and behavioral effects of psychostimulants. II: cocaine intravenous selfadministration and reinstatement depend on glucocorticoid levels. J Pharmacol Exp Ther 281:1401-1407. Medline

Diorio D, Viau V, Meaney MJ (1993) The role of the medial prefrontal cortex (cingulate gyrus) in the regulation of hypothalamic-pituitaryadrenal responses to stress. J Neurosci 13:3839-3847. Medline

Divac I (1971) Frontal lobe system and spatial reversal in the rat. Neuropsychologia 9:175-183. CrossRef Medline
Dumitriu D, Hao J, Hara Y, Kaufmann J, Janssen WG, Lou W, Rapp PR, Morrison JH (2010) Selective changes in thin spine density and morphology in monkey prefrontal cortex correlate with aging-related cognitive impairment. J Neurosci 30:7507-7515. CrossRef Medline

Dumitriu D, Laplant Q, Grossman YS, Dias C, Janssen WG, Russo SJ, Morrison JH, Nestler EJ (2012) Subregional, dendritic compartment, and spine subtype specificity in cocaine regulation of dendritic spines in the nucleus accumbens. J Neurosci 32:6957-6966. CrossRef Medline

Erb S, Shaham Y, Stewart J (1998) The role of corticotropin-releasing factor and corticosterone in stress- and cocaine-induced relapse to cocaine seeking in rats. J Neurosci 18:5529-5536. Medline

Erb S, Hitchcott PK, Rajabi H, Mueller D, Shaham Y, Stewart J (2000) Alpha-2 adrenergic receptor agonists block stress-induced reinstatement of cocaine seeking. Neuropsychopharmacology 23:138-150. CrossRef Medline

Ettenberg A (2004) Opponent process properties of self-administered cocaine. Neurosci Biobehav Rev 27:721-728. CrossRef Medline

Figueiredo HF, Bruestle A, Bodie B, Dolgas CM, Herman JP (2003) The medial prefrontal cortex differentially regulates stress-induced c-fos expression in the forebrain depending on type of stressor. Eur J Neurosci 18:2357-2364. CrossRef Medline

Galici R, Pechnick RN, Poland RE, France CP (2000) Comparison of noncontingent versus contingent cocaine administration on plasma corticosterone levels in rats. Eur J Pharmacol 387:59-62. CrossRef Medline

George O, Mandyam CD, Wee S, Koob GF (2008) Extended access to cocaine self-administration produces long-lasting prefrontal cortexdependent working memory impairments. Neuropsychopharmacology 33:2474-2482. CrossRef Medline

Goeders NE (2002) The HPA axis and cocaine reinforcement. Psychoneuroendocrinology 27:13-33. CrossRef Medline

Goeders NE, Guerin GF, Schmoutz CD (2014) The combination of metyrapone and oxazepam for the treatment of cocaine and other drug addictions. Adv Pharmacol 69:419-479. CrossRef Medline

Goldman-Rakic PS (1995) Cellular basis of working memory. Neuron 14: 477-485. CrossRef Medline

Goldstein RZ, Volkow ND (2011) Dysfunction of the prefrontal cortex in addiction: neuroimaging findings and clinical implications. Nat Rev Neurosci 12:652-669. CrossRef Medline

Gourley SL, Olevska A, Warren MS, Taylor JR, Koleske AJ (2012) Arg kinase regulates prefrontal dendritic spine refinement and cocaine-induced plasticity. J Neurosci 32:2314-2323. CrossRef Medline

Gourley SL, Swanson AM, Koleske AJ (2013) Corticosteroid-induced neural remodeling predicts behavioral vulnerability and resilience. J Neurosci 33:3107-3112. CrossRef Medline

Hains AB, Vu MA, Maciejewski PK, van Dyck CH, Gottron M, Arnsten AF (2009) Inhibition of protein kinase $C$ signaling protects prefrontal cortex dendritic spines and cognition from the effects of chronic stress. Proc Natl Acad Sci U S A 106:17957-17962. CrossRef Medline

Harris KM, Stevens JK (1989) Dendritic spines of CA 1 pyramidal cells in the rat hippocampus: serial electron microscopy with reference to their biophysical characteristics. J Neurosci 9:2982-2997. Medline

Heesch CM, Negus BH, Keffer JH, Snyder RW 2nd, Risser RC, Eichhorn EJ (1995) Effects of cocaine on cortisol secretion in humans. Am J Med Sci 310:61-64. CrossRef Medline

Hester R, Garavan H (2004) Executive dysfunction in cocaine addiction: evidence for discordant frontal, cingulate, and cerebellar activity. J Neurosci 24:11017-11022. Medline

Holtmaat AJ, Trachtenberg JT, Wilbrecht L, Shepherd GM, Zhang X, Knott GW, Svoboda K (2005) Transient and persistent dendritic spines in the neocortex in vivo. Neuron 45:279-291. CrossRef Medline

Jentsch JD, Taylor JR (1999) Impulsivity resulting from frontostriatal dysfunction in drug abuse: implications for the control of behavior by reward-related stimuli. Psychopharmacology 146:373-390. CrossRef Medline

Kaufman JN, Ross TJ, Stein EA, Garavan H (2003) Cingulate hypoactivity in cocaine users during a GO-NOGO task as revealed by event-related functional magnetic resonance imaging. J Neurosci 23:7839-7843. Medline

Kirov SA, Petrak LJ, Fiala JC, Harris KM (2004) Dendritic spines disappear with chilling but proliferate excessively upon rewarming of mature hippocampus. Neuroscience 127:69-80. CrossRef Medline

Knott GW, Holtmaat A, Wilbrecht L, Welker E, Svoboda K (2006) Spine 
growth precedes synapse formation in the adult neocortex in vivo. Nat Neurosci 9:1117-1124. CrossRef Medline

LaLumiere RT, Kalivas PW (2008) Glutamate release in the nucleus accumbens core is necessary for heroin seeking. J Neurosci 28:3170-3177. CrossRef Medline

LaLumiere RT, Smith KC, Kalivas PW (2012) Neural circuit competition in cocaine-seeking: roles of the infralimbic cortex and nucleus accumbens shell. Eur J Neurosci 35:614-622. CrossRef Medline

LaPlant Q, Vialou V, Covington HE 3rd, Dumitriu D, Feng J, Warren BL, Maze I, Dietz DM, Watts EL, Iñiguez SD, Koo JW, Mouzon E, Renthal W, Hollis F, Wang H, Noonan MA, Ren Y, Eisch AJ, Bolaños CA, Kabbaj M, et al. (2010) Dnmt3a regulates emotional behavior and spine plasticity in the nucleus accumbens. Nat Neurosci 13:1137-1143. CrossRef Medline

Lee KW, Kim Y, Kim AM, Helmin K, Nairn AC, Greengard P (2006) Cocaine-induced dendritic spine formation in D1 and D2 dopamine receptor-containing medium spiny neurons in nucleus accumbens. Proc Natl Acad Sci U S A 103:3399-3404. CrossRef Medline

Liston C, Miller MM, Goldwater DS, Radley JJ, Rocher AB, Hof PR, Morrison JH, McEwen BS (2006) Stress-induced alterations in prefrontal cortical dendritic morphology predict selective impairments in perceptual attentional set-shifting. J Neurosci 26:7870-7874. CrossRef Medline

Liston C, Cichon JM, Jeanneteau F, Jia Z, Chao MV, Gan WB (2013) Circadian glucocorticoid oscillations promote learning-dependent synapse formation and maintenance. Nat Neurosci 16:698-705. CrossRef Medline

Liu RJ, Aghajanian GK (2008) Stress blunts serotonin- and hypocretinevoked EPSCs in prefrontal cortex: role of corticosterone-mediated apical dendritic atrophy. Proc Natl Acad Sci U S A 105:359-364. CrossRef Medline

Lucantonio F, Caprioli D, Schoenbaum G (2014) Transition from 'modelbased' to 'model-free' behavioral control in addiction: Involvement of the orbitofrontal cortex and dorsolateral striatum. Neuropharmacology 76: 407-415. CrossRef Medline

Mantsch JR, Cullinan WE, Tang LC, Baker DA, Katz ES, Hoks MA, Ziegler DR (2007) Daily cocaine self-administration under long-access conditions augments restraint-induced increases in plasma corticosterone and impairs glucocorticoid receptor-mediated negative feedback in rats. Brain Res 1167:101-111. CrossRef Medline

Mantsch JR, Weyer A, Vranjkovic O, Beyer CE, Baker DA, Caretta H (2010) Involvement of noradrenergic neurotransmission in the stress- but not cocaine-induced reinstatement of extinguished cocaine-induced conditioned place preference in mice: role for beta- 2 adrenergic receptors. Neuropsychopharmacology 35:2165-2178. CrossRef Medline

Marinelli M, Rougé-Pont F, Deroche V, Barrot M, De Jésus-Oliveira C, Le Moal M, Piazza PV (1997) Glucocorticoids and behavioral effects of psychostimulants. I: locomotor response to cocaine depends on basal levels of glucocorticoids. J Pharmacol Exp Ther 281:1392-1400. Medline

McEwen BS, Morrison JH (2013) The brain on stress: vulnerability and plasticity of the prefrontal cortex over the life course. Neuron 79:16-29. CrossRef Medline

McFarland K, Kalivas PW (2001) The circuitry mediating cocaine-induced reinstatement of drug-seeking behavior. J Neurosci 21:8655-8663. Medline

McFarland K, Lapish CC, Kalivas PW (2003) Prefrontal glutamate release into the core of the nucleus accumbens mediates cocaine-induced reinstatement of drug-seeking behavior. J Neurosci 23:3531-3537. Medline

Mendelson JH, Teoh SK, Mello NK, Ellingboe J, Rhoades E (1992) Acute effects of cocaine on plasma adrenocorticotropic hormone, luteinizing hormone and prolactin levels in cocaine-dependent men. J Pharmacol Exp Ther 263:505-509. Medline

Moldow RL, Fischman AJ (1987) Cocaine induced secretion of ACTH, betaendorphin, and corticosterone. Peptides 8:819-822. CrossRef Medline

Morrison JH, Baxter MG (2012) The ageing cortical synapse: hallmarks and implications for cognitive decline. Nat Rev Neurosci 13:240-250. Medline

Muñoz-Cuevas FJ, Athilingam J, Piscopo D, Wilbrecht L (2013) Cocaineinduced structural plasticity in frontal cortex correlates with conditioned place preference. Nat Neurosci 16:1367-1369. CrossRef Medline

Nemeroff CB, Krishnan KR, Reed D, Leder R, Beam C, Dunnick NR (1992) Adrenal gland enlargement in major depression: a computed tomographic study. Arch Gen Psychiatry 49:384-387. CrossRef Medline

Nimchinsky EA, Sabatini BL, Svoboda K (2002) Structure and function of dendritic spines. Annu Rev Physiol 64:313-353. CrossRef Medline
Palamarchouk V, Smagin G, Goeders NE (2009) Self-administered and passive cocaine infusions produce different effects on corticosterone concentrations in the medial prefrontal cortex (MPC) of rats. Pharmacol Biochem Behav 94:163-168. CrossRef Medline

Pelloux Y, Murray JE, Everitt BJ (2013) Differential roles of the prefrontal cortical subregions and basolateral amygdala in compulsive cocaine seeking and relapse after voluntary abstinence in rats. Eur J Neurosci 38:3018 3026. Medline

Radley JJ, Rocher AB, Miller M, Janssen WG, Liston C, Hof PR, McEwen BS, Morrison JH (2006) Repeated stress induces dendritic spine loss in the rat medial prefrontal cortex. Cereb Cortex 16:313-320. Medline

Radley JJ, Rocher AB, Rodriguez A, Ehlenberger DB, Dammann M, McEwen BS, Morrison JH, Wearne SL, Hof PR (2008) Repeated stress alters dendritic spine morphology in the rat medial prefrontal cortex. J Comp Neurol 507:1141-1150. CrossRef Medline

Radley JJ, Gosselink KL, Sawchenko PE (2009) A discrete GABAergic relay mediates medial prefrontal cortical inhibition of the neuroendocrine stress response. J Neurosci 29:7330-7340. CrossRef Medline

Radley JJ, Anderson RM, Hamilton BA, Alcock JA, Romig-Martin SA (2013) Chronic stress-induced alterations of dendritic spine subtypes predict functional decrements in an hypothalamo-pituitary-adrenal-inhibitory prefrontal circuit. J Neurosci 33:14379-14391. CrossRef Medline

Radley J, Morilak D, Viau V, Campeau S (2015) Chronic stress and brain plasticity: mechanisms underlying adaptive and maladaptive changes and implications for stress-related CNS disorders. Neurosci Biobehav Rev pii: S0149-7634(15)00172-4. CrossRef Medline

Ramos BP, Birnbaum SG, Lindenmayer I, Newton SS, Duman RS, Arnsten AF (2003) Dysregulation of protein kinase a signaling in the aged prefrontal cortex: new strategy for treating age-related cognitive decline. Neuron 40:835-845. CrossRef Medline

Rassnick S, Heinrichs SC, Britton KT, Koob GF (1993) Microinjection of a corticotropin-releasing factor antagonist into the central nucleus of the amygdala reverses anxiogenic-like effects of ethanol withdrawal. Brain Res 605:25-32. CrossRef Medline

Rivier C, Vale W (1987) Cocaine stimulates adrenocorticotropin (ACTH) secretion through a corticotropin-releasing factor (CRF)-mediated mechanism. Brain Res 422:403-406. CrossRef Medline

Robinson TE, Kolb B (1999) Alterations in the morphology of dendrites and dendritic spines in the nucleus accumbens and prefrontal cortex following repeated treatment with amphetamine or cocaine. Eur J Neurosci 11:1598-1604. CrossRef Medline

Robinson TE, Kolb B (2004) Structural plasticity associated with exposure to drugs of abuse. Neuropharmacology 47:33-46. CrossRef Medline

Robinson TE, Gorny G, Mitton E, Kolb B (2001) Cocaine self-administration alters the morphology of dendrites and dendritic spines in the nucleus accumbens and neocortex. Synapse 39:257-266. Medline

Rodriguez A, Ehlenberger DB, Hof PR, Wearne SL (2006) Rayburst sampling, an algorithm for automated three-dimensional shape analysis from laser scanning microscopy images. Nat Protoc 1:2152-2161. CrossRef Medline

Rubin RT, Poland RE, Lesser IM, Winston RA, Blodgett AL (1987) Neuroendocrine aspects of primary endogenous depression. I. Cortisol secretory dynamics in patients and matched controls. Arch Gen Psychiatry 44:328-336. CrossRef Medline

Saphier D, Welch JE, Farrar GE, Goeders NE (1993) Effects of intracerebroventricular and intrahypothalamic cocaine administration on adrenocortical secretion. Neuroendocrinology 57:54-62. CrossRef Medline

Sarnyai Z, Bíró E, Gardi J, Vecsernyés M, Julesz J, Telegdy G (1995) Brain corticotropin-releasing factor mediates 'anxiety-like' behavior induced by cocaine withdrawal in rats. Brain Res 675:89-97. CrossRef Medline

Shen HW, Toda S, Moussawi K, Bouknight A, Zahm DS, Kalivas PW (2009) Altered dendritic spine plasticity in cocaine-withdrawn rats. J Neurosci 29:2876-2884. CrossRef Medline

Stefanik MT, Moussawi K, Kupchik YM, Smith KC, Miller RL, Huff ML, Deisseroth K, Kalivas PW, LaLumiere RT (2013) Optogenetic inhibition of cocaine seeking in rats. Addict Biol 18:50-53. CrossRef Medline

Sudai E, Croitoru O, Shaldubina A, Abraham L, Gispan I, Flaumenhaft Y, Roth-Deri I, Kinor N, Aharoni S, Ben-Tzion M, Yadid G (2011) High cocaine dosage decreases neurogenesis in the hippocampus and impairs working memory. Addict Biol 16:251-260. CrossRef Medline 
Sun W, Rebec GV (2006) Repeated cocaine self-administration alters processing of cocaine-related information in rat prefrontal cortex. J Neurosci 26:8004-8008. CrossRef Medline

Twining RC, Bolan M, Grigson PS (2009) Yoked delivery of cocaine is aversive and protects against the motivation for drug in rats. Behav Neurosci 123:913-925. CrossRef Medline

Ulrich-Lai YM, Herman JP (2009) Neural regulation of endocrine and autonomic stress responses. Nat Rev Neurosci 10:397-409. CrossRef Medline

Ulrich-Lai YM, Figueiredo HF, Ostrander MM, Choi DC, Engeland WC, Herman JP (2006) Chronic stress induces adrenal hyperplasia and hypertrophy in a subregion-specific manner. Am J Physiol Endocrinol Metab 291:E965-973. CrossRef Medline

Vescovi PP, Coiro V, Volpi R, Giannini A, Passeri M (1992) Hyperthermia in sauna is unable to increase the plasma levels of ACTH/cortisol, betaendorphin and prolactin in cocaine addicts. J Endocrinol Invest 15:671675. CrossRef Medline

Wellman CL (2001) Dendritic reorganization in pyramidal neurons in medial prefrontal cortex after chronic corticosterone administration. J Neurobiol 49:245-253. CrossRef Medline

Whitfield TW Jr, Shi X, Sun WL, McGinty JF (2011) The suppressive effect of an intraprefrontal cortical infusion of BDNF on cocaine-seeking is Trk receptor and extracellular signal-regulated protein kinase mitogenactivated protein kinase dependent. J Neurosci 31:834-842. CrossRef Medline

Yuste R, Bonhoeffer T (2001) Morphological changes in dendritic spines associated with long-term synaptic plasticity. Ann Rev Neurosci 24:10711089. CrossRef Medline 